\title{
A dynamic and thermodynamic coupling view of the linkages between Eurasian cooling and Arctic warming
}

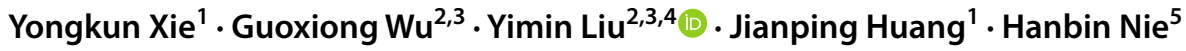

Received: 11 May 2021 / Accepted: 24 October 2021 / Published online: 2 November 2021

(c) The Author(s) 2021

\begin{abstract}
Investigating the contrast between wintertime warming in the Arctic and cooling in Eurasia is of great importance for understanding regional climate change. In this study, we propose a dynamic and thermodynamic coupling view of the linkages between wintertime Arctic warming and Eurasian cooling since 1979. The key factors are the energy budget at the Earth's surface, the diabatic heating and baroclinicity of the atmosphere, and subsurface ocean heat. A summertime origin of wintertime Arctic warming suggests a partial driving role of the Arctic in wintertime Eurasian cooling. The reasons for this finding are as follows. First, there is a dipole pattern in the diabatic heating change in winter over the Arctic Ocean corresponding to the anticyclonic circulation that links Eurasian cooling and Arctic warming. Second, the change in diabatic heating of the atmosphere is determined by sensible heat at the Earth's surface through vertical diffusion. Third, the positive sensible heat change in the eastern Arctic sector in winter originates from the summertime enhanced absorption of solar radiation by the subsurface ocean over the sea ice loss region. Meanwhile, the negative sensible heat change in the western Arctic sector and wide Arctic warming can be explained by the circulation development triggered by the change in the east. Additionally, the background strong baroclinicity of the atmosphere in mid-high latitudes and corresponding two-way Arctic and mid-latitude interactions are necessary for circulation development in winter. Furthermore, the seasonality of the changes indicates that Eurasian cooling occurs only in winter because the diabatic heating change in the Arctic is strongest in winter. Overall, the comprehensive mechanisms from the summertime Earth's surface and subsurface ocean to the wintertime atmosphere suggest a driving role of the Arctic. Note that the situation in interannual variability is more complex than the overall trend because the persistence of the influence of summertime sea ice is weakly established in terms of interannual variability.
\end{abstract}

Keywords Eurasian cooling $\cdot$ Arctic warming $\cdot$ Energy budget $\cdot$ Diabatic heating $\cdot$ Baroclinicity $\cdot$ Sea ice $\cdot$ Ocean

Yimin Liu

lym@lasg.iap.ac.cn

1 Collaborative Innovation Center for Western Ecological Safety, Lanzhou University, Lanzhou, China

2 State Key Laboratory of Numerical Modeling for Atmospheric Sciences and Geophysical Fluid Dynamics (LASG), Institute of Atmospheric Physics, Chinese Academy of Sciences, Beijing, China

3 College of Earth and Planetary Sciences, University of Chinese Academy of Sciences, Beijing, China

4 CAS Center for Excellence in Tibetan Plateau Earth Sciences, Beijing, China

5 College of Atmospheric Sciences, Lanzhou University, Lanzhou, China

\section{Introduction}

As one of the most remarkable features of global warming, amplified Arctic warming has received intensive attention and has been the subject of a wide range of studies (Shepherd 2016; Stouffer and Manabe 2017). On the one hand, studies have explored the characteristics and causes of the amplification of Arctic warming relative to the rest of the globe (e.g., Holland and Bitz 2003; Cai 2005; Winton 2006; Dai et al. 2019; Xie et al. 2019). On the other hand, studies have explored the local and remote influences of amplified Arctic warming and Arctic sea ice variations (e.g., Alexander et al. 2004; Screen and Simmonds 2013; Schneider et al. 2015; Yang et al. 2016; Xie et al. 2020).

Wide attention has yielded substantial investigations of the connection between the Arctic and Eurasia. For example, Alexander et al. (2004) propose that wintertime Arctic 
warming over the Atlantic Ocean sector can affect Eurasia by generating circulation anomalies resembling the Arctic oscillation and North Atlantic oscillation; meanwhile, they suggest that Arctic warming over the Pacific Ocean sector can generate a stationary wave train that affects North America. Honda et al. (2009) and Nakamura et al. (2015) propose that amplified warming around the Barents-Kara Sea can stimulate an anomalous stationary wave train that induces an enhanced Siberian high, and eventually cold conditions in Eurasia. Francis and Vavrus (2015) propose that Arctic warming can affect the pattern of the jet stream and the associated weather extremes. Luo et al. (2016) suggest the crucial role of Ural blocking in connecting the warm Arctic with cold Eurasia. Zhang et al. (2018) suggest that the stratospheric pathway is important.

The aforementioned pathways can work separately or synergistically. For example, Li et al. (2019) and Zhang et al. (2020) suggest that warming over the Barents-Kara Seas can affect wintertime cooling over China through stationary waves, jet streams, Ural blocking, the Siberian High, and the East Asian winter monsoon. To simplify the complex network built by multiple pathways, Xie et al. (2020) proposed a potential vorticity view of the dynamics in the interior atmosphere. Beyond the multiple pathways, one key question is the divergence in the conclusions in previous studies regarding the role of Arctic amplification and sea ice in the observed Eurasian cooling (e.g., reviewed by Cohen et al. (2020) and Blackport and Screen (2020b), and debates such as between Mori et al. (2021) and Zappa et al. (2021)). Many divergent conclusions are caused by the difference in interpretations rather than the results. The conclusions are quite sensitive to the domains (e.g., the whole Arctic or a specific region), time scale (e.g., overall trend or interannual variability), and seasons. Hence, the scope of this study is restricted to the Barents-Kara seas, from summer to winter, and mainly in overall trend (1979-2017) but also with interannual and decadal variability involved (as schematically shown in Fig. 17). Comprehensive connections among the atmosphere, Earth's surface, and the ocean are proposed in this paper. Overall, this study provides several new interpretations of the Arctic and Eurasian connections. Some of our findings, such as the comparison between the overall trend and interannual variability and the role of background baroclinicity and corresponding two-way interactions, could help to understand the existing divergence. Additionally, this study is also helpful in understanding the discrepancies among the multimodel simulations (Smith et al. 2019).

This paper examines Eurasian cooling and Arctic warming since 1979. The underlying dynamics are explored from a general dynamic and thermodynamic coupling view. The view is based on the energy budget at the Earth's surface, the diabatic heating of the atmosphere, and the ocean heat states and transports. The remainder of this paper is arranged into seven parts. Section 2 describes the data and methods used in this paper. The essential characteristics, e.g., spatial pattern and vertical structure, of Eurasian cooling and Arctic warming are presented in Sect. 3. Section 4 demonstrates the changes in the energy budget at the Earth's surface and sea ice. Section 5 explores the linkage between the energy budget at the Earth's surface and the diabatic heating of the atmosphere. Section 6 addresses the seasonality in the changes of the circulation, temperature, and diabatic heating of the atmosphere and the role of baroclinicity. Section 7 explores the role of ocean heat transport and the complexity of the interannual and decadal variability. Concluding remarks are presented in Sect. 8.

\section{Data and methods}

\subsection{Reanalysis data}

ERA-Interim (ERA-I) and NCEP-DOE Reanalysis-2 (NCEP-2) reanalysis data are used in this study. Detailed information on the variables examined is listed in Table 1. We use three groups of ERA-I data, including data archived at the Earth's surface, pressure levels, and model levels. The Earth's surface and pressure-level data are monthly means, while the model-level data are six-hourly instantaneous values. The data examined are for the period from 1979 to 2018. The numbers of vertical levels are 37 for the pressure-level data and 60 for the model-level data. The lowest model level is nearly $10 \mathrm{~m}$ high (Table 2 in Berrisford et al. 2011a). The chosen resolution for the Earth's surface data and pressure-level data is $1.5^{\circ} \times 1.5^{\circ}$, and for the model-level data, it is $2.5^{\circ} \times 2.5^{\circ}$, while the original model resolution for producing ERA-I data is $\sim 0.75^{\circ}$ (Dee et al. 2011). The NCEP-2 data are archived at 28 vertical sigma levels, in a global T62 Gaussian grid, and available for the period from 1979 to 2014 (Kanamitsu et al. 2002).

\subsection{Sea ice concentration}

We use the sea ice concentration data provided by the Met Office Hadley Centre. Sea ice concentration is defined as the percentage of a grid area covered by sea ice. The data have a horizontal resolution of $1^{\circ} \times 1^{\circ}$ latitude by longitude (Rayner et al. 2003). The dataset covers the period from 1870 to the present day and is available as the monthly mean. The data are available at https://www.metoffice.gov.uk/hadobs/hadis st/data/download.html.

\subsection{Subsurface ocean temperature}

We use the subsurface ocean temperature data provided by the Met Office Hadley Centre. The subsurface ocean 
Table 1 Information on the variables from ERA-I and NCEP-2

\begin{tabular}{|c|c|c|c|}
\hline \multicolumn{4}{|l|}{ ERA-I } \\
\hline \multirow[t]{7}{*}{ Earth's surface } & Monthly & $2 \mathrm{~m}$ temperature $(\mathrm{t} 2 \mathrm{~m})$ & Skin temperature (skt) \\
\hline & & Mean sea level pressure (msl) & $10 \mathrm{~m} \mathrm{U}$ wind component (u10) \\
\hline & & $10 \mathrm{~m}$ V wind component (v10) & \\
\hline & Synoptic & Surface sensible heat flux (sshf, $H_{\mathrm{S}}^{\uparrow}$ ) & Surface latent heat flux (slhf, $H_{\mathrm{L}}^{\uparrow}$ ) \\
\hline & $\begin{array}{l}\text { monthly } \\
\text { means }\end{array}$ & Surface net solar radiation (ssr, $R_{\mathrm{SW}}^{\downarrow}-R_{\mathrm{SW}}^{\uparrow}$ ) & Surface net solar radiation, clear sky (ssrc) \\
\hline & & Surface solar radiation downwards (ssrd, $R_{\mathrm{SW}}^{\downarrow}$ ) & Surface net thermal radiation ( $\mathrm{str}, R_{\mathrm{LW}}^{\downarrow}-R_{\mathrm{LW}}^{\uparrow}$ ) \\
\hline & & Surface thermal radiation downwards (strd, $\left.R_{\mathrm{LW}}^{\downarrow}\right)$ & \\
\hline \multirow[t]{2}{*}{ Pressure-level } & Monthly & Temperature (t) & Geopotential (z) \\
\hline & & U component of wind $(\mathrm{u})$ & V component of wind $(\mathrm{v})$ \\
\hline \multirow[t]{3}{*}{ Model-level } & Six-hourly & Temperature (t) & Geopotential (z) \\
\hline & & $\mathrm{U}$ component of wind $(\mathrm{u})$ & V component of wind $(\mathrm{v})$ \\
\hline & & Vertical velocity (w) & Logarithm of surface pressure (lnsp) \\
\hline \multicolumn{4}{|l|}{ NCEP-2 } \\
\hline \multirow[t]{3}{*}{ Sigma-level } & Monthly & Solar radiative heating (swhrsig, $Q_{S W}$ ) & Longwave radiative heating (lwhrsig, $Q_{L W}$ ) \\
\hline & & Vertical diffusion heating (vdfhrsig, $Q_{V D}$ ) & Large scale condensation heating (lrghrsig, $Q_{L C}$ ) \\
\hline & & Deep convective heating (cnvhrsig, $Q_{D C}$ ) & Shallow convective heating (shahrsig, $Q_{S C}$ ) \\
\hline
\end{tabular}

The original name of each variable in the data file is marked in brackets. The variable names corresponding to the variables in Eqs. (1) and (4) are also provided in parentheses

temperature data are produced by objective analyses of the observed subsurface ocean temperature profiles (Good et al. 2013). The dataset is in version 4.2.1 with corrections by Gouretski and Reseghetti (2010) and marked as EN4.2.1. The data have a horizontal resolution of $1^{\circ} \times 1^{\circ}$ latitude by longitude and 42 vertical levels. The dataset covers the period from 1900 to the present day and is available as the monthly mean. The data are available at https://www.metof fice.gov.uk/hadobs/en4/download-en4-2-1.html. The variable examined is the potential temperature of the sea water and labelled "temperature" within the data file.

\subsection{The Arctic Ocean horizontal heat and freshwater transport}

We use the horizontal heat and freshwater transport data across the Arctic gateways published in PANGAEA. The Arctic gateways are marked in Fig. 16. Heat and freshwater transport are inverse estimates based on observations (Tsubouchi et al. 2019). The dataset covers the period from October 2004 to May 2010 and is available as the monthly mean. The data is available at https://doi.org/10.1594/PANGAEA. 909966. The variables examined are pan-Arctic total and Barents Sea opening (BSO) heat and freshwater transport.

\subsection{Energy budget at the Earth's surface}

For the Earth's surface, the local energy budget is
$E_{\mathrm{net}}^{\downarrow}=R_{\mathrm{SW}}^{\downarrow}-R_{\mathrm{SW}}^{\uparrow}+R_{\mathrm{LW}}^{\downarrow}-R_{\mathrm{LW}}^{\uparrow}-H_{\mathrm{S}}^{\uparrow}-H_{\mathrm{L}}^{\uparrow}$,

where $R_{\mathrm{SW}}^{\downarrow}$ and $R_{\mathrm{SW}}^{\uparrow}$ indicate the incoming and outgoing shortwave solar radiation, $R_{\mathrm{LW}}^{\downarrow}$ and $R_{\mathrm{LW}}^{\uparrow}$ indicate the incoming and outgoing longwave thermal infrared radiation, and $H_{\mathrm{S}}^{\uparrow}$ and $H_{\mathrm{L}}^{\uparrow}$ indicate the upward sensible and latent heat fluxes. Note that the sensible and latent heat fluxes are also widely referred to as turbulent heat fluxes. $E_{\text {net }}^{\downarrow}$ indicates the net energy, which involves both the local heat uptake and the horizontal energy transport and is calculated indirectly according to Eq. (1). The original variable information in ERA-I data corresponding to the variables in Eq. (1) are listed in Table 1.

\subsection{Diabatic heating of the atmosphere}

For the atmosphere, there is no detailed energy budget such as Eq. (1) available in the ERA-I reanalysis. Instead, diabatic heating based on the thermodynamic equation is examined. In particular, the diabatic heating of the atmosphere can directly quantify the energy gain or loss of the atmosphere due to changes in the energy budget at the Earth's surface. The total diabatic heating of the atmosphere is represented by the material change rate of the potential temperature and is formulated for the model-level data as,

$\dot{\theta}=\partial_{t} \theta+\underbrace{\boldsymbol{V} \cdot \boldsymbol{\nabla} \theta}_{\dot{\theta}_{h}}+\underbrace{\omega_{m l} \partial_{p} \theta}_{\dot{\theta}_{v}}$, 
$\omega_{m l}=\omega-\partial_{t} p-u \partial_{x} p-v \partial_{y} p$,

where $\theta$ indicates the potential temperature and the vectors (bold type) $\boldsymbol{V}$ and $\boldsymbol{\nabla}$ indicate the horizontal wind velocity ( $u$, $v, 0)$ and the three-dimensional gradient operator, respectively. Note that the symbols of all the variables are consistent with Appendix B of the textbook Holton (2004). $\omega_{m l}$ indicates the vertical velocity at the model-level adjusted according to the vertical coordinate transformation rules. As addressed in Sheng et al. (2021), the deduction process is as follows: the material change rate of $\theta(x, y, \mathrm{~h}, t)$ is $\dot{\theta}=\partial_{t} \theta+\boldsymbol{V} \cdot \boldsymbol{\nabla} \theta+\dot{\mathrm{h}} \partial_{\mathrm{h}} \theta$ when marking the vertical hybrid sigma-pressure coordinate of the model level as $h$. Similarly, the material change rate of the pressure, i.e., the original vertical velocity provided in the model-level data, is $\omega=\dot{p}=\partial_{t} p+\boldsymbol{V} \cdot \boldsymbol{\nabla} p+\dot{\mathrm{h}} \partial_{\mathrm{h}} p$. By solving $\dot{\mathrm{h}}$, we obtain $\dot{\mathrm{h}}=\left(\omega-\partial_{t} p-\boldsymbol{V} \cdot \boldsymbol{\nabla} p\right) / \partial_{\mathrm{h}} p$. Finally, introducing the formula of $\dot{h}$ to the formula of $\dot{\theta}$, we obtain Eqs. (2) and (3). $\dot{\theta}_{h}$ and $\dot{\theta}_{v}$ represent the diabatic heating directly connected with the horizontal circulation and thermal contrast and the vertical motion and static stability, respectively. The diabatic heating is directly calculated from the six-hourly instantaneous data.

To further verify the diabatic heating derived from the model-level data according to Eq. (2), diabatic heating based on the physical types from NCEP-2 sigma-level data is further examined. The six diabatic heating components are solar $\left(Q_{S W}\right)$ and longwave $\left(Q_{L W}\right)$ radiative, vertical diffusion $\left(Q_{V D}\right)$, large-scale condensation $\left(Q_{L C}\right)$, and deep $\left(Q_{D C}\right)$ and shallow $\left(Q_{S C}\right)$ convective heating. The sum of the six components is the total diabatic heating

$Q=Q_{S W}+Q_{L W}+Q_{V D}+Q_{L C}+Q_{D C}+Q_{S C}$.

The NCEP-2 sigma-level diabatic heating $Q$ is in units of $\mathrm{Ks}^{-1}$. The original variable information in NCEP-2 data corresponding to the variables in Eq. (4) are listed in Table 1. Hence, the two kinds of diabatic heating of the atmosphere, i.e., $\dot{\theta}$ and $Q$, are comparable because they are the same in units and physical meaning.

Some further clarifications about the diabatic heatingrelated method are addressed here. The first clarification concerns the energy conservation problem, as raised by Trenberth (1991), Chiodo and Haimberger (2010), and Berrisford et al. (2011b). The so-called energy conservation problem is the imbalance between the two sides of the energy equation in the reanalysis because of the interpolation process; namely, the vertical integral of the divergence of the total energy differs from the net energy forcing through the top of the atmosphere and Earth's surface. The energy conservation problem can be partly solved by the empirical barotropic adjustment method, as addressed in detail by Hill et al. (2017). However, the adjustment at each single vertical level is very small. The vertical integral amplifies the small bias at each single level. Such an energy conservation problem also exists for the derived diabatic heating $\dot{\theta}$ according to Eq. (2). Nevertheless, energy conservation does not affect our conclusions because we focus on the individual level and the vertical profile. Additionally, our results regarding diabatic heating $\dot{\theta}$ are further verified by NECP-2 diabatic heating $Q$.

Another clarification is about the choice of thermodynamic equation-based diabatic heating $\dot{\theta}$ rather than other choices, e.g., the total energy or the moist (or dry) static energy. The pros and cons of several common approaches are discussed. Thermodynamic equation-based diabatic heating $\dot{\theta}$ is one of the most concise in form and convenient in calculation. Importantly, thermodynamic equation-based diabatic heating $\dot{\theta}$ can be conveniently verified by directly available diabatic heating data, e.g., NCEP-2 or MERRA-2 (on pressure levels, not shown) data. Meanwhile, for the advantages of energy-based approaches, energy has a readily understandable physical meaning (e.g., Yanai et al. (1973)). Actually, for a dry atmosphere, $Q_{1}$ in Yanai et al. (1973) has a simple relation with the diabatic heating of the atmosphere in this paper as $Q_{1}=c_{p}\left(p / p_{0}\right)^{\kappa} \dot{\theta}$ in pressure coordinates, e.g., Eq. (3) in Holopainen and Fortelius (1986). In addition, the energy associated with latent heat, e.g., the total energy and moist static energy, can conveniently be used to explore the role of the moist process (Graversena and Burtu 2016; Hill et al. 2017). It should be noted that the influence of the latent heat release has been inherently included in the derived $\dot{\theta}$, although latent heat is not explicitly formulated in Eq. (2). Nevertheless, the influence of the bias in the moisture process (e.g., Lindsay et al. 2014; Liu and Key 2016) in the reanalysis on the results is not clear. Additionally, the diabatic heating components provided by NCEP-2 help to examine the role of different physical processes.

Several typically developed methods relating to thermodynamic equation-based diabatic heating $\dot{\theta}$ are discussed here. One category of development is the transformation of the form of the thermodynamic equation. In general, this kind of development has a more complex formulation than our Eq. (2). For example, Holopainen and Fortelius (1986) and Nigam (1994) proposed another form that involves both temperature and potential temperature and adopted mean-eddy decomposition, e.g., Eq. (2) in Nigam (1994). In practice, the form of the thermodynamic equation can be transformed into various forms according to specific purposes. However, the different formulations are identical in nature, and the form in our Eq. (2) is one of the most concise. The other category can be classified as isentropic analysis. For example, Iwasaki et al. (2014) proposed a method of isentropic analysis of a polar cold airmass. The method is based on the isentropic mass continuity equation that involves diabatic heating $\dot{\theta}$, as indicated by Eq. (2) in Iwasaki et al. (2014). In another example, Papritza and Spengler 
(2015) proposed an isentropic analysis method on the slope of isentropic surfaces. The tendency equation of the slope of the isentropic surface also involves diabatic heating $\dot{\theta}$, as indicated by Eq. (11) in Papritza and Spengler (2015). Overall, this kind of isentropic analysis method is very useful in determining the dynamics associated with the Arctic and mid-latitude connections. Further studies will try to use these methods.

\subsection{Diagnostic methods}

The linear trend is calculated from the least-squares estimator-based linear regression. The corresponding significance was estimated by using the two-tailed Student's t-test. The spatial pattern correlation coefficient is calculated as the Pearson product-moment coefficient used in the well-known Taylor Diagram (Taylor 2001). The linear correlation coefficient of the two time series is calculated as the Pearson sample linear cross-correlations. The corresponding statistical significance was estimated by the two-tailed Pearson's r-test. The boreal winter is defined as the three-month period from December to the following February.

\section{Features of Eurasian cooling and Arctic warming}

As indicated by the wintertime temperature changes during 1979-2017 (Fig. 1a), the Arctic warming amplification is remarkable. The warming trend is generally statistically significant across the Arctic and the strongest warming is observed around the Barents-Kara seas. Meanwhile, cooling in the extratropical Eurasian continent, i.e., Eurasian cooling, is also observed. This cooling is generally statistically insignificant except for some points (Fig. 1a). However, the Eurasian cooling indicated by the surface skin temperature (Fig. 1b) is more significant than that of the near-surface temperature (Fig. 1a). The results from ERA-I reanalysis

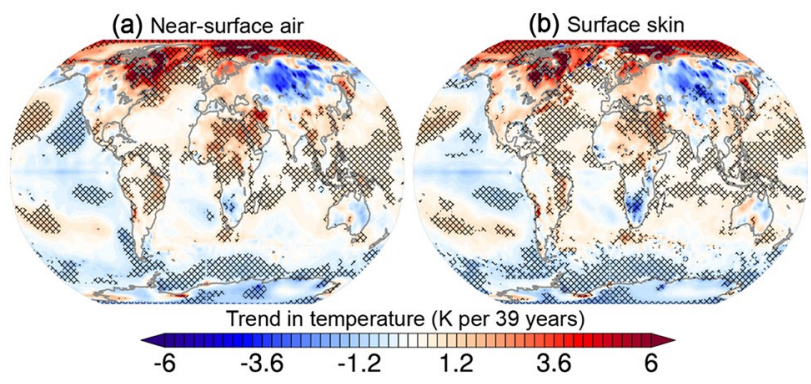

Fig. 1 Linear trend in the near-surface air temperature (a) and surface skin temperature (b) from 1979 to 2017 during boreal winter. The linear trend in the hatched areas is significant at the $95 \%$ confidence level based on a two-tailed Student's t-test are consistent with the observation-based results, such as those from GISTEMP data shown in Fig. 1a in Xie et al. (2020). The ERA-I reanalysis data generally show larger magnitudes of temperature changes than observations at the regional scale, namely, warmer changes over warming regions and cooler changes over cooling regions. However, the smooth distribution of temperature change in the observation is probably due to the original coarse resolution of the observational sites.

To determine further characteristics, the temperature and circulation changes at other vertical levels are also examined. Eurasian cooling and Arctic warming occur not only at the surface but also throughout almost the entire troposphere (not shown). As a typical choice, $500 \mathrm{hPa}$ is chosen for further analysis. As governed by the geostrophic balance, the wind field (not shown) fits the geopotential height very well. However, the relationship between temperature and circulation is not simple. There are apparent cross-isotherm wind changes near the Earth's surface in the sector of Eurasian cooling and Arctic warming (Fig. 2a), namely, a baroclinic structure. A prominent anticyclonic circulation
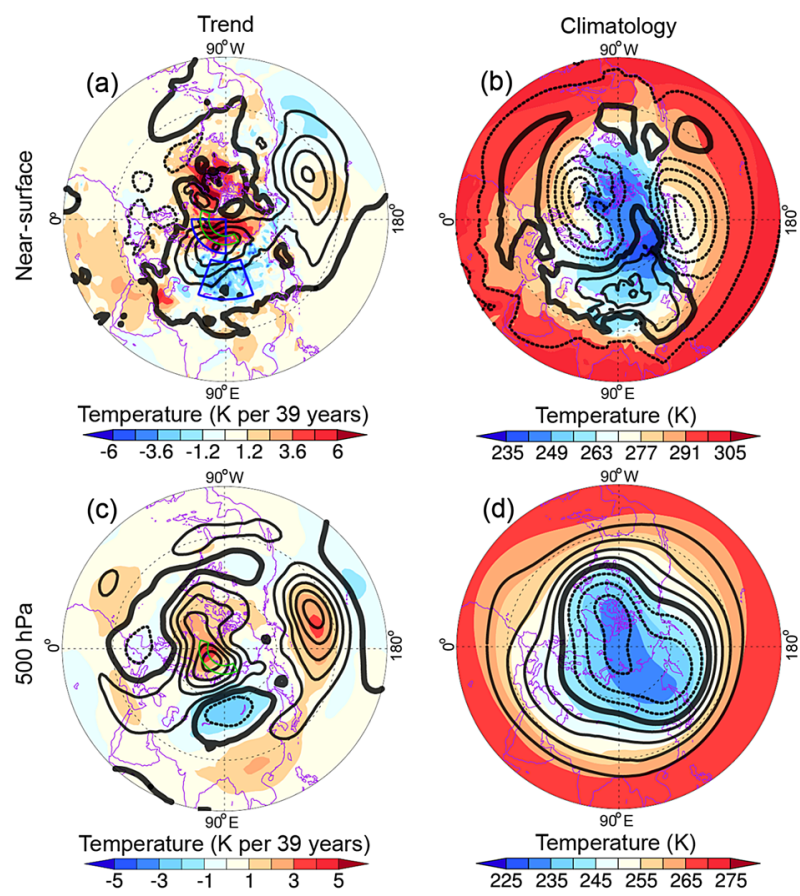

Fig. 2 a Linear trend in temperature (filled) at the near-surface and sea level pressure (black contour) from 1979 to 2017 during boreal winter. The dashed and solid black lines represent negative and positive values, respectively; the interval is $2 \mathrm{hPa}$ and the thick line is zero. The blue sectors outline the key regions focused on in this study. The green sector in the Arctic and Eurasia outlines the region examined in Fig. 12a. b Same as a but for the climatology. The interval of the black contours is $5 \mathrm{hPa}$ and the thick contour is $1020 \mathrm{hPa}$. (Bottom) Same as (top) but for the results at $500 \mathrm{hPa}$. The black contours indicate geopotential height; the interval in c is $20 \mathrm{gpm}$; the interval in $\mathbf{d}$ is $100 \mathrm{gpm}$; and the thick line is $5300 \mathrm{gpm}$ 
change spanning that sector directly links Eurasian cooling with Arctic warming (Fig. 2a). The east flank of the anticyclonic circulation change tends to advect cold air from the Arctic to Eurasia (Figs. 2a, b), favouring Eurasian cooling (Fig. 2a). Meanwhile, the west flank of the anticyclonic circulation anomaly also tends to advect warm air from the mid-latitudes to the Arctic, favouring Arctic warming. Overall, the baroclinic structure suggests that there are two-way interactions between the Arctic and mid-latitudes, as further indicated by the baroclinic wave feature shown in Fig. 12. Namely, the seamless feedback between temperature advection and circulation development is crucial for climatological mean Eurasian cooling and Arctic warming.

In the middle troposphere ( $500 \mathrm{hPa}$; Fig. 2 bottom), the circulation is more organized than that at the near-surface. Additionally, in contrast to the near-surface conditions (Fig. 2a), the circulation changes at $500 \mathrm{hPa}$ almost overlap with the temperature changes (Fig. 2c). The anticyclonic circulation change over the Arctic and Eurasian sectors is still evident at $500 \mathrm{hPa}$ (but westward relative to the surface), while an apparent cyclonic change presents over the Eurasian cooling region. Compared with the climatology (Fig. 2d), the circulation change to the north of the cyclonic anomaly weakens the climatological westerlies and vice versa for the south flank. Consistent with the circulation changes, the temperature gradient decreased over the area where the circulation weakened and vice versa, which suggests a thermal wind relation.

Weakened high-latitude westerlies are frequently blamed for the increase in mid-latitude weather extremes (Cohen et al. 2014; Huang et al. 2017; Luo et al. 2018). However, in the climate sense, circulation change should not be regarded as the fundamental reason for temperature change. The consistent changes in temperature and circulation reflect the coupling between temperature and circulation (Yeh and Chu 1958). Therefore, more analyses are needed to clarify the causality.

\section{Changes in the energy budget at the Earth's surface and sea ice}

The local energy budget at the Earth's surface (Eq. (1), addressed in Sect. 2.5) is examined to understand the regional temperature changes. Figure 3 shows the wintertime changes in each energy budget term included in Eq. (1). For the Earth's surface, the net solar radiation $\left(R_{\mathrm{SW}}^{\downarrow}-R_{\mathrm{SW}}^{\uparrow}\right)$ and incoming longwave radiation $\left(R_{\mathrm{LW}}^{\downarrow}\right)$ can be considered energy "forces", while the outgoing longwave radiation $\left(R_{\mathrm{LW}}^{\uparrow}\right)$, sensible heat $\left(H_{\mathrm{S}}^{\uparrow}\right)$, and latent heat $\left(H_{\mathrm{L}}^{\uparrow}\right)$ are the "responses" associated with the redistribution of the incoming energy. As shown in Fig. 3, incoming longwave radiation has a dominant contribution to both Eurasian cooling and Arctic warming around the Barents-Kara seas (key regions are marked with green borders). Wintertime solar radiation does not influence Arctic warming because of the polar night. Solar radiation favours part of southern Eurasian cooling.

The incoming longwave radiation is just a superficial reason rather than the fundamental reason. For any region with
Fig. 3 Linear trend in the net shortwave radiation $\left(R_{\mathrm{SW}}^{\downarrow}-R_{\mathrm{SW}}^{\uparrow}, \mathbf{a}\right)$, incoming longwave radiation $\left(R_{\mathrm{LW}}^{\downarrow}, \mathbf{b}\right)$, outgoing longwave radiation $\left(R_{\mathrm{LW}}^{\uparrow}, \mathbf{c}\right)$, net longwave radiation $\left(R_{\mathrm{LW}}^{\mathrm{LW}}-R_{\mathrm{LW}}^{\uparrow}, \mathbf{d}\right)$, outgoing sensible heat $\left(H_{\mathrm{S}}^{\uparrow}, \mathbf{e}\right)$, and outgoing latent heat $\left(H_{\mathrm{L}}^{\uparrow}, \mathbf{f}\right)$ at the Earth's surface from 1979 to 2017 during boreal winter. The pattern correlation coefficient between $R_{\mathrm{LW}}^{\downarrow}(\mathbf{b})$ and $R_{\mathrm{LW}}^{\uparrow}(\mathbf{c})$ is 0.9 . The pattern correlation coefficient between $H_{\mathrm{S}}^{\uparrow}(\mathbf{e})$ and $H_{\mathrm{L}}^{\uparrow}(\mathbf{f})$ is -0.7 . The linear trend in the hatched areas is significant at the $95 \%$ confidence level based on a two-tailed Student's t-test
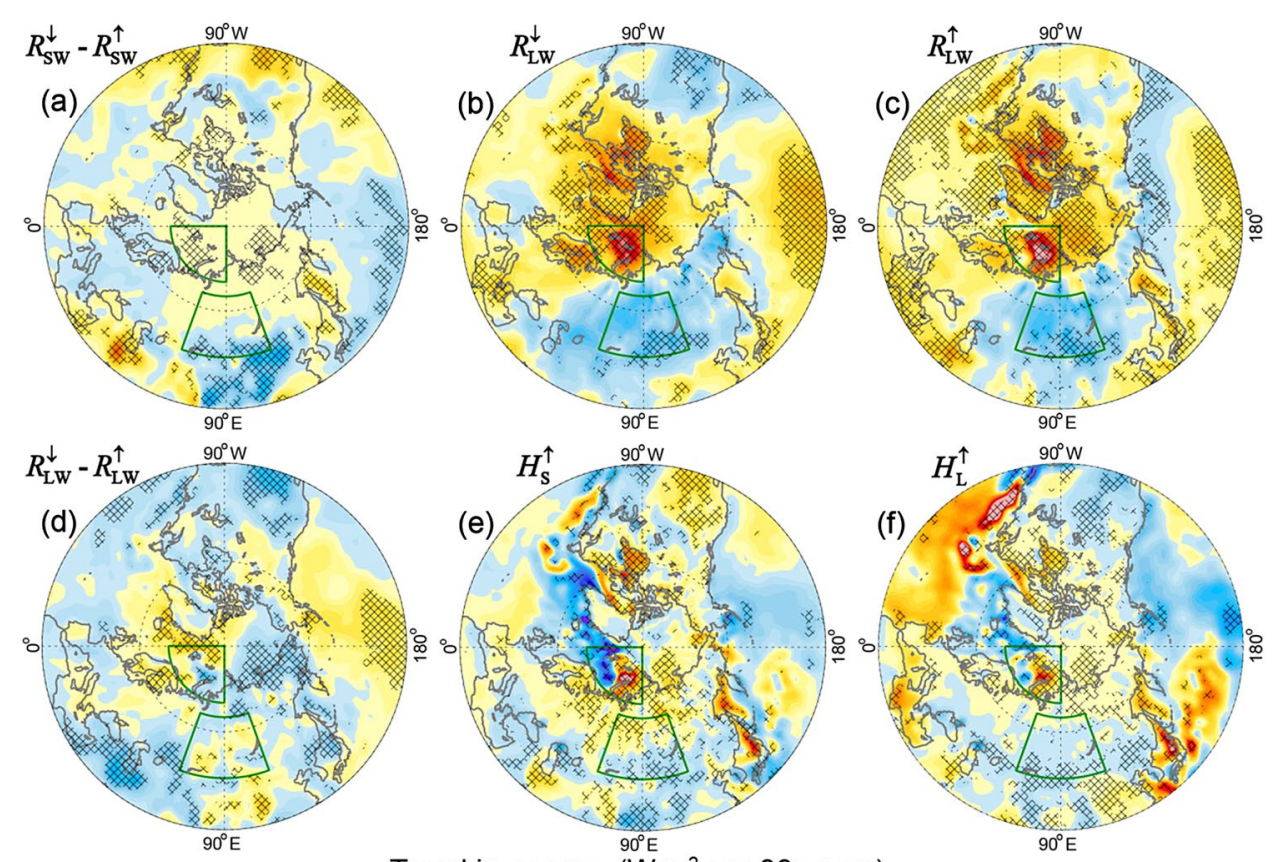

(e)
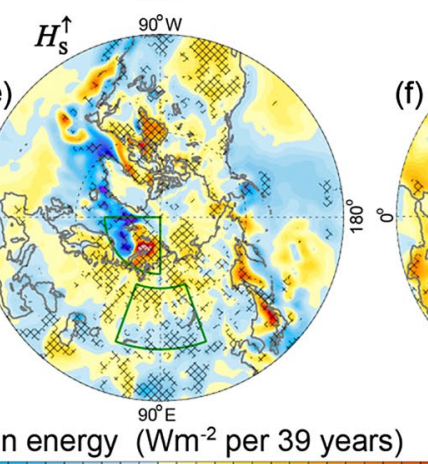

Trend in energy ( $\mathrm{Wm}^{-2}$ per 39 years)

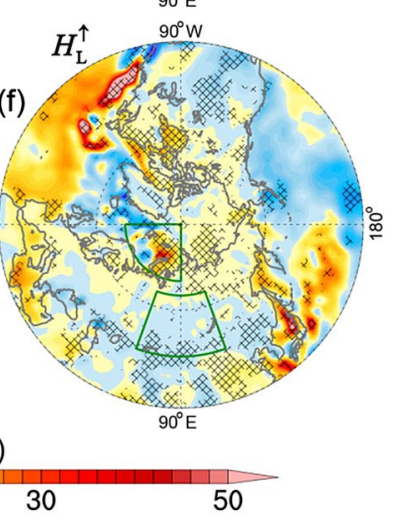


substantial warming, the simultaneous incoming longwave radiation must be increased. This is because the feedback processes between the incoming and outgoing longwave radiation result in their generally coordinated changes (the pattern correlation coefficient between Fig. 3b, c is up to $0.9)$. Consequently, as determined by the Stefan-Boltzmann law, the temperature change also highly agrees with the longwave radiation. Although the incoming longwave radiation change and associated longwave feedback are indispensable, the ultimate question is to explore the contribution of water vapor, clouds, and energy sources ( $E_{\text {net }}^{\downarrow}$ herein) at the Earth's surface to the observed incoming longwave radiation change. For example, Kapsch et al. (2013) suggest that the springtime transport of moisture to the Arctic and associated water vapor and cloudiness anomalies are crucial for the subsequent summertime sea ice anomaly. Additionally, previous studies indicate that the water vapor change mainly acts to modulate wintertime warming, and it is the existence of clouds rather than the change that is more crucial for summertime albedo feedback and wintertime warming over sea ice change regions (Screen and Simmonds 2013; Dai et al. 2019; He et al. 2019; Xie et al. 2019). Therefore, the mechanisms regarding the change in energy budget at the Earth's surface should be further evaluated.

In addition to the energy "forces", the energy "responses" are also examined. The redistribution of the outgoing energy between sensible and latent heat largely determines the final surface skin temperature change. Considering the ideal case when the anomalous input energy was totally released by the latent heat, the input energy cannot change the surface skin temperature because all the energy was consumed by evaporation. In contrast, the surface skin temperature and the near-surface air temperature must change when the input energy is released by the sensible heat. Figure $3 e, f$ indicate that the sensible heat change is generally consistent with the latent heat change in sign but with a much larger magnitude over the Arctic Ocean. For a positive change, sensible heat directly warms the near-surface atmosphere, while latent heat acts to suppress the warming of the near-surface atmosphere by consuming part of the input energy through evaporation. Nonetheless, latent heat can directly affect the atmospheric temperature through the condensation heat of clouds and precipitation, which is further addressed using diabatic heating of the atmosphere from NCEP-2 data. As shown in Fig. 11h, the condensation heating (sum of the large-scale condensation $\left(Q_{L C}\right)$, deep $\left(Q_{D C}\right)$ and shallow $\left(Q_{S C}\right)$ convective heating) related to surface latent heat is much weaker than the vertical diffusion heating due to sensible heat. Hence, the role of the surface sensible heat is more crucial than the surface latent heat.

For an exact balanced local energy budget without local energy uptake and horizontal energy transport, the net energy ( $\left.E_{\text {net }}^{\downarrow}\right)$ on the left-hand side of Eq. (1) will be zero. However, hysteretic features in the energy cycle at the Earth's surface, e.g., over a region with a large heat capacity, indicate that the local energy uptake cannot be ignored in this study during the examination of seasonal-scale phenomena. For example, climate model simulations by Laîné et al. (2016) and Yoshimori et al. (2017) suggest that greenhouse gas increase-induced changes in the mixed layer temperature and energy uptake/release in the Arctic Ocean have prominent seasonal cycles. Herein we will specifically examine whether the energy cycle is crucial for the observed climate changes during the past several decades. Since the local energy uptake and horizontal energy transport are not available in ERA-I data, the net energy is indirectly determined according to Eq. (1).

As observed in Fig. 4d, the wintertime net energy change in the Arctic warming region shows a similar pattern but opposite sign as sensible heat (Fig. 3e). Additionally, the change in net longwave radiation is much weaker relative to sensible heat (Fig. 3d, e; also see later Fig. 8c, d). These results indicate that an enhanced net energy release accompanies an increased sensible heat and vice versa. By comparing the net energy changes in the four seasons, the pattern of wintertime net energy change in the Arctic warming region (Fig. 4d) is similar to that in autumn (Fig. 4c) but is opposite
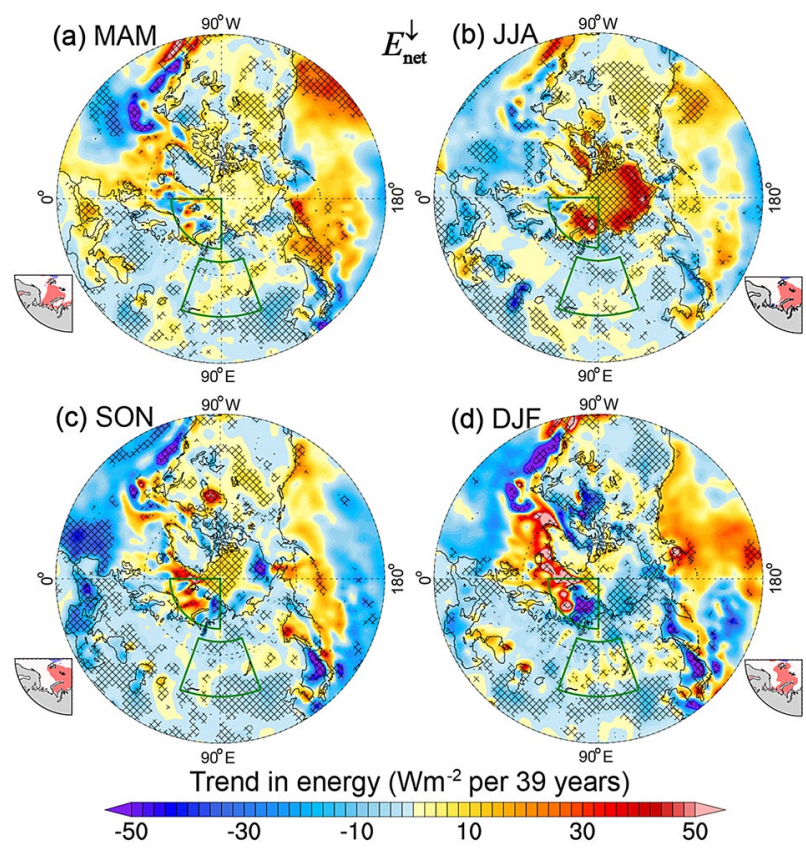

Fig. 4 Linear trend in net energy $\left(E_{\text {net, }}^{\downarrow}\right.$ Eq. (1)) at the Earth's surface from 1979 to 2017 during boreal spring (a), summer (b), autumn (c), and winter (d). The pink fill in the attached piece to each figure indicates the regions with sea ice loss; specifically, the regions with a negative linear trend in sea ice concentration larger than $5 \%$ per 39 years, as shown in Fig. 5. The linear trend in the hatched areas is significant at the $95 \%$ confidence level based on a two-tailed Student's t-test 
to that in summer (Fig. 4b). Hence, the energy cycle in the Arctic warming region can be summarized as summertime enhanced (weakened) energy uptake regulating the wintertime enhanced (weakened) energy release. However, for the region with weakened wintertime energy release in the Arctic warming region (positive change in Fig. 4d, western part of the Arctic sector), the summertime weakened energy uptake is too small to dominate the change in the winter. In particular, the summertime weakened energy uptake in the western Arctic sector is statistically insignificant (Fig. 4b). Hence, the weakened wintertime energy release in the western Arctic sector may be regulated by other factors, such as the two-way interactions of the atmosphere between the Arctic and mid-latitudes and ocean heat transport (further addressed in Sects. 6 and 7).

The regions with strong net energy changes in the Arctic (Fig. 4) overlap with the regions with strong sea ice changes (Fig. 5). Here, the different outermost latitudes in Figs. 4 and 5 should be noted when comparing any specific locations across the two maps. In the summer, the region with enhanced energy uptake in the Arctic Ocean is the region with strong sea ice loss. In the winter, the region with enhanced energy release is also the region with strong sea ice loss. Summertime sea ice loss helps simultaneous energy uptake through albedo feedback, while wintertime sea ice loss helps simultaneous energy release by favouring heat exchange between the ocean and atmosphere (Dai

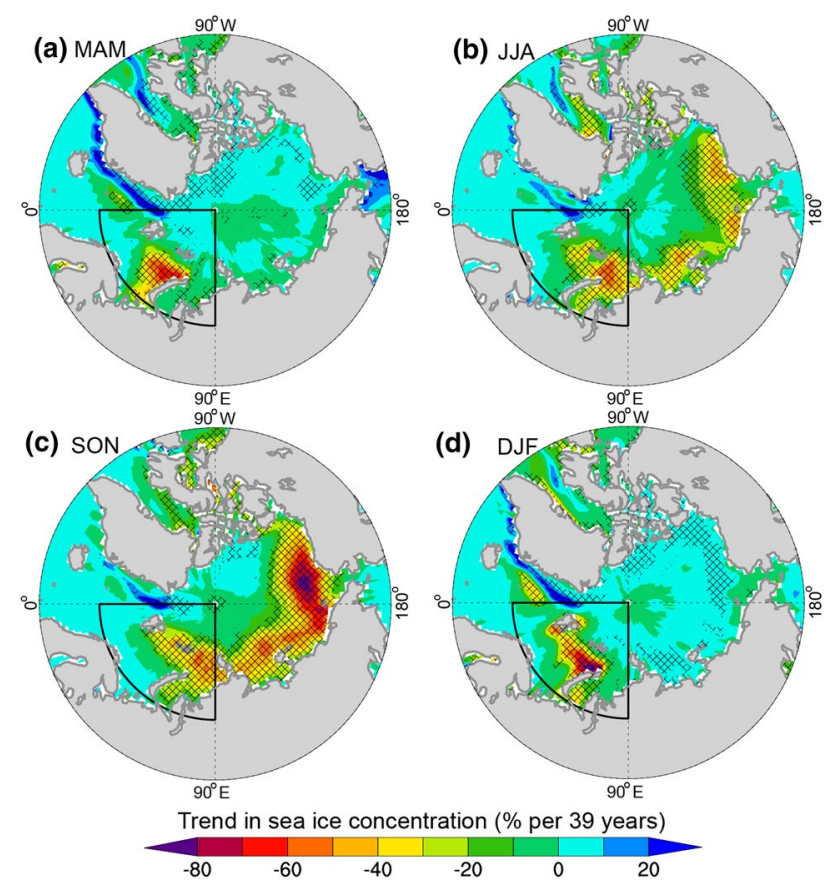

Fig. 5 Linear trend in the sea ice concentration from 1979 to 2017 during the four seasons. The outermost latitude of the map is $60^{\circ} \mathrm{N}$. The linear trend in the hatched areas is significant at the $95 \%$ confidence level based on a two-tailed Student's t-test et al. 2019). Additionally, regarding sea ice change, the sea ice loss in the Pacific sector in autumn (Fig. 5c) is quite prominent. However, there is no corresponding strong net energy change (Fig. 4c). This is because the albedo feedback in autumn (figures not shown) is weaker than that in summer (Fig. 9) when the incoming solar radiation in autumn is much weaker than that in summer (figures not shown).

\section{Linkage between the energy budget at the Earth's surface and the diabatic heating of the atmosphere}

The local energy budget at the Earth's surface directly connects with the surface skin temperature. As already addressed in Sect. 2.6, diabatic heating based on the thermodynamic equation $(\dot{\theta})$ and provided by the NCEP-2 data $(Q)$ is used to describe the atmosphere. As shown in Fig. $6 a$, the pattern of the change in the diabatic heating of the near-surface air $(\dot{\theta})$ resembles that of sensible heat at the Earth's surface (Fig. 3e). In particular, the change in diabatic heating of the atmosphere (both $\dot{\theta}$ and $Q$, Fig. 6a, b) highly agrees with the sensible heat change (Fig. 3e) in the Arctic sector. $\dot{\theta}$ and $Q$ do not agree with each other in the Eurasian sector (Fig. 6a, b). Nevertheless, for both $\dot{\theta}$ and $Q$, the magnitudes of the changes in the Arctic sector
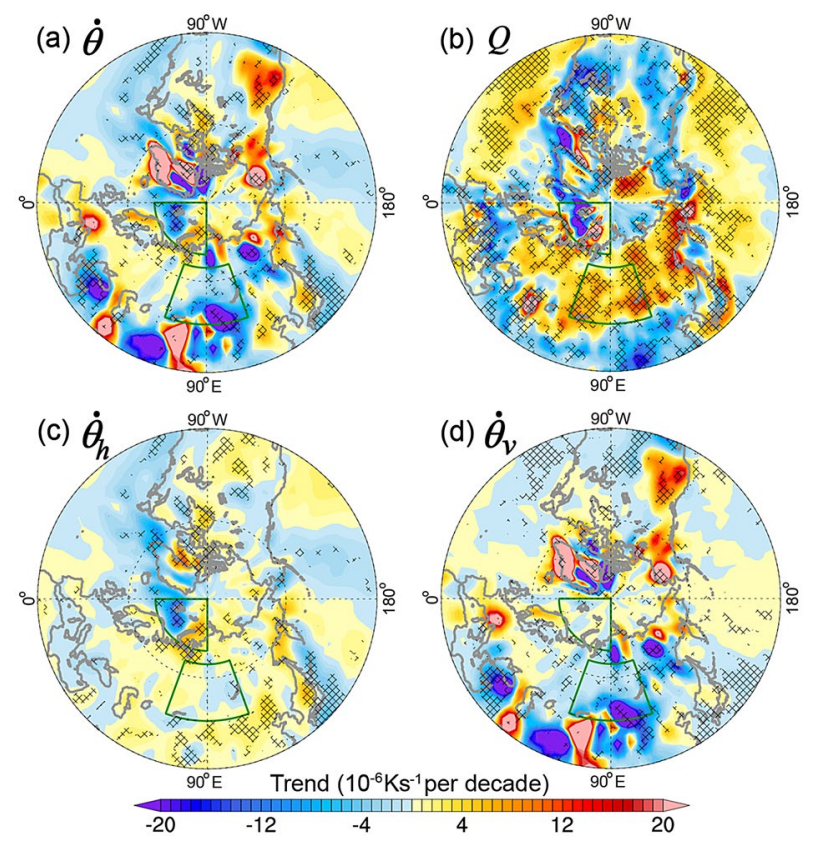

Fig. 6 a Linear trend in $\dot{\theta}$ (Eq. (2)) at the lowest model-level ( $10 \mathrm{~m})$ of ERA-I data from 1979 to 2017 during boreal winter. b Same as a but for the linear trend (1979-2013) in $Q$ at the lowest sigma-level (Eq. (4)) of NCEP-2 data. c, d Same as a but for the linear trend in $\dot{\theta}_{h}$ and $\dot{\theta}_{v}$, respectively. The linear trend in the hatched areas is significant at the $95 \%$ confidence level based on a two-tailed Student's t-test 
are larger than those in the Eurasian sector when the singular values of $\dot{\theta}_{v}$ are filtered from $\dot{\theta}$. Additionally, for the western Arctic sector, the negative change in $Q$ and sensible heat is statistically insignificant (Figs. 3e, 6b), although the negative change in $\dot{\theta}$ is significant (Fig. 6a). Taken together, the positive diabatic heating change in the eastern Arctic sector is more crucial because it is more significant and has a summertime origin. In addition, further analysis will show that the negative diabatic heating change in the western Arctic sector in winter can be modulated by the eastern region through the development of circulation.

The changes in the six components of $Q$ (Fig. 7) indicate that the change in $Q$ is dominated by vertical diffusion $\left(Q_{V D}\right)$, which represents the effect of sensible heat. To date, the results robustly suggest a central role of sensible heat at the Earth's surface in determining the change in wintertime diabatic heating of the atmosphere in the Arctic sector (Figs. 3e, $6 a, b, 7 a)$. Furthermore, the connections between the summer and winter energy changes are verified by examining the annual cycle of energy change. As shown in Fig. 8a, for the western and eastern regions relative to $50^{\circ} \mathrm{E}$, there is weakened (positive) and enhanced (negative) energy release during the wintertime in the Arctic Ocean, respectively. The change in the eastern sector is statistically significant, while the change in the western sector is insignificant.

For the eastern Arctic sector, the enhanced summertime energy uptake due to the absorption of solar radiation (Fig. 8b) is then released in the wintertime through sensible heat (Fig. 8c). During this process, the change in absorption of solar radiation (Fig. 8b) is related to sea ice loss (Fig. 5b) and the corresponding albedo feedback in summer. As shown in Fig. 9, both incoming and outgoing solar radiation decreased due to clouds, but the net absorption of solar radiation still increased due to albedo feedback in summer (He et al. 2019; Xie et al. 2019).

The statements verified by the multiple datasets and evidence in the last section and this section are recapped here to make the points clear. For the eastern Arctic sector, albedo feedback generates enhanced summertime energy uptake through the absorption of more solar radiation in the sea ice loss region (Figs. 4b, 5b, 8a, b, 9a). The additional energy stored by the Arctic Ocean in the summer is then released in the winter through sensible heat (Figs. 3e, 4d, $8 \mathrm{a}, \mathrm{c})$. The enhanced sensible heat at the Earth's surface then directly heats the atmosphere above through diabatic heating (Figs. 3e, 6a, b, 7a). Since the energy cycle originates in summer, the causality is clear.

\section{Seasonality in the changes of the circulation, temperature, and diabatic heating of the atmosphere and the role of baroclinicity}

The aforementioned results demonstrate the connections between the energy budget at the Earth's surface (from summer to winter) and the wintertime diabatic heating of the atmosphere in the Arctic sector. However, to complete the story, further elaboration of the linkages from the diabatic
Fig. 7 Linear trend in the six components of $Q$ (Eq. (4)) at the lowest sigma-level of NCEP-2 from 1979 to 2013 during boreal winter. The six components are solar $\left(Q_{S W}\right)$ and longwave $\left(Q_{L W}\right)$ radiative, vertical diffusion $\left(Q_{V D}\right)$, largescale condensation $\left(Q_{L C}\right)$, and deep $\left(Q_{D C}\right)$ and shallow $\left(Q_{S C}\right)$ convective heating. The linear trend in the hatched areas is significant at the $95 \%$ confidence level based on a two-tailed Student's t-test
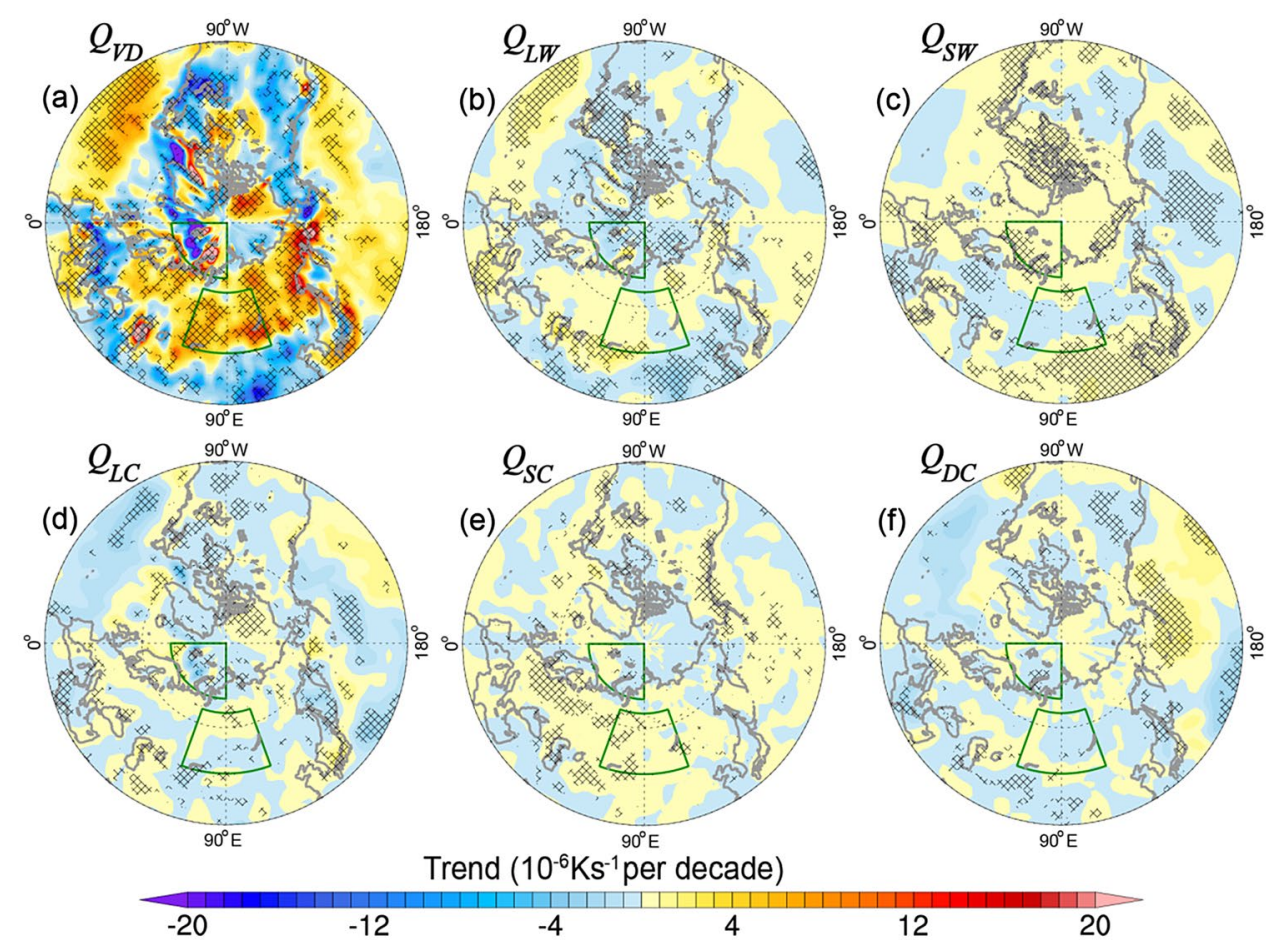

(e)
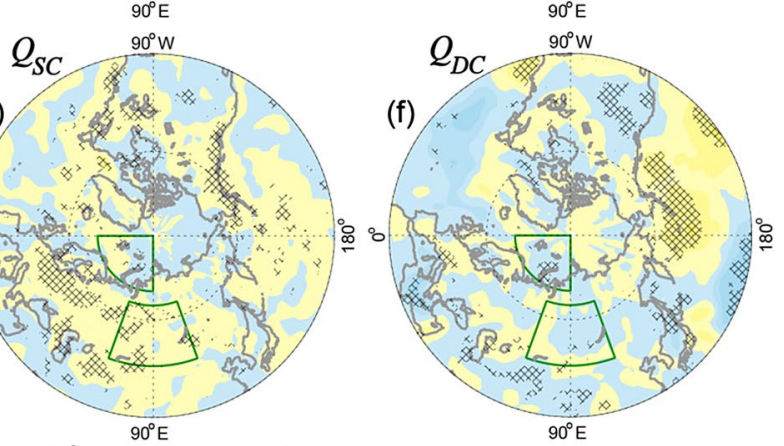

Trend $\left(10^{-6} \mathrm{Ks}^{-1}{ }^{90^{\circ} \mathrm{E}}\right.$ per decade)
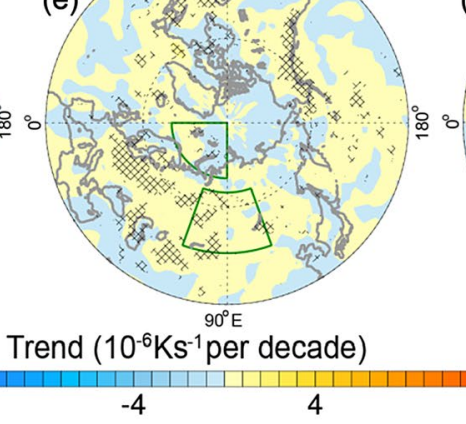

4

12

20 

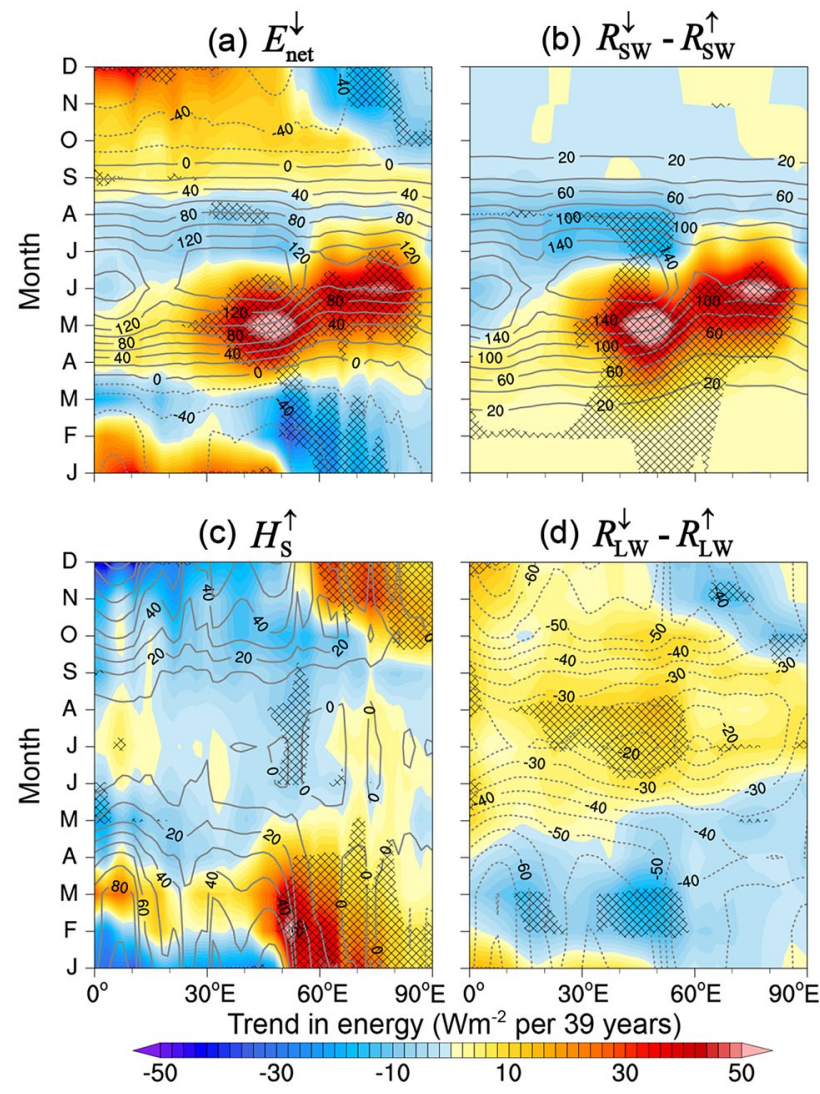

Fig. 8 Linear trend in monthly mean net energy $\left(E_{\text {net }}^{\downarrow}, \mathbf{a}\right)$, net shortwave radiation $\left(R_{\mathrm{SW}}^{\downarrow}-R_{\mathrm{SW}}^{\uparrow}, \mathbf{b}\right)$, outgoing sensible heat $\left(H_{\mathrm{S}}^{\uparrow}\right.$, $\left.\mathbf{c}\right)$, and net longwave radiation $\left(R_{\mathrm{LW}}^{\downarrow}-R_{\mathrm{LW}}^{\uparrow}, \mathbf{d}\right)$ at the Earth's surface averaged over $\left[70^{\circ} \mathrm{N}-80^{\circ} \mathrm{N}\right]$ from 1979 to 2017 . The linear trend in the hatched areas is significant at the $95 \%$ confidence level based on a two-tailed Student's t-test. The overlapping grey contours indicate the climatological values

heating of the atmosphere to the circulation and temperature of the atmosphere is needed. As addressed in Sect. 3, an anticyclonic circulation changes at the near-surface and dipole circulation changes aloft (anticyclones in the Arctic and cyclones in Eurasia) are crucial in linking wintertime Arctic warming and Eurasian cooling (Fig. 2a, c). To verify this, further investigations on the seasonality of the changes in the circulation, temperature, and diabatic heating of the atmosphere are performed.

Figure 10 presents the changes in the atmospheric temperature and circulation near the Earth's surface and at $500 \mathrm{hPa}$ in each month. Throughout the year, cooling in the large areas of the Eurasian continent near the Earth's surface only occurs in winter (DJF). In contrast, except for summer (JJA), warming in the Arctic occurs most of the months. Therefore, the Arctic warming and Eurasian cooling correspondence exists only during the winter. In the months without correspondence (MAMSON), the strongest Arctic warming is generally located more east than that in winter.

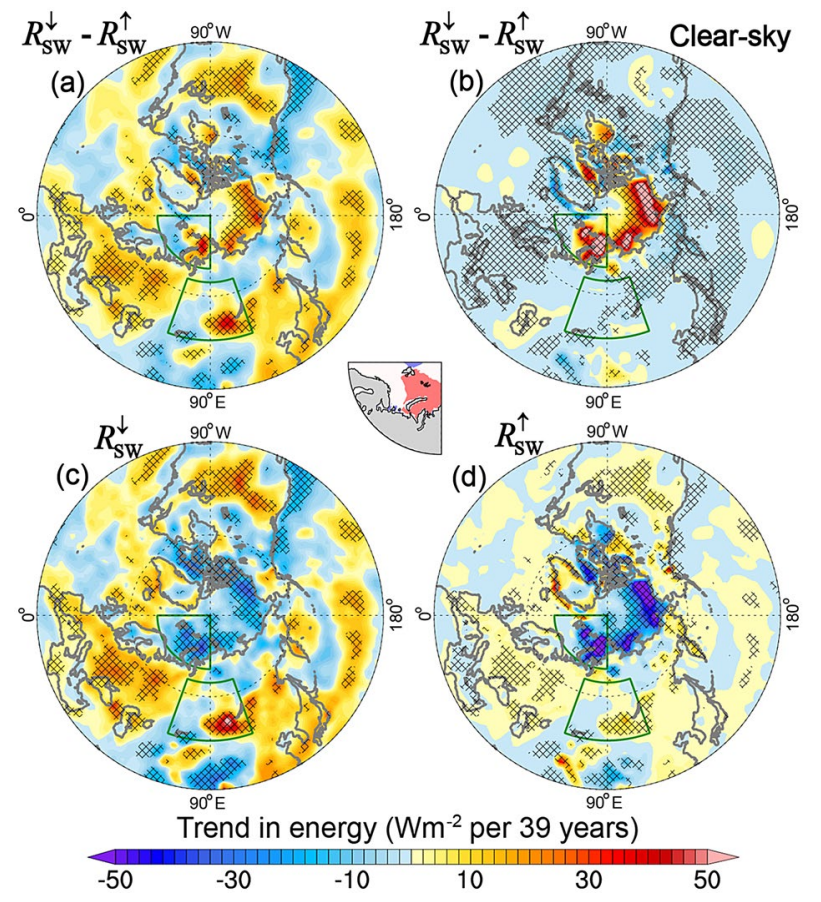

Fig. 9 Linear trend in the net shortwave radiation $\left(R_{\mathrm{SW}}^{\downarrow}-R_{\mathrm{SW}}^{\uparrow}, \mathbf{a}\right)$, incoming shortwave radiation $\left(R_{\mathrm{SW}}^{\downarrow}, \mathbf{c}\right)$, and outgoing shortwave radiation $\left(R_{\mathrm{SW}}^{\uparrow}, \mathbf{d}\right)$ at the Earth's surface from 1979 to 2017 during boreal summer. b Same as a but for the clear-sky result. The pink fill in the attached piece indicates the regions with a negative linear trend in sea ice concentration larger than 5\% per 39 years. The linear trend in the hatched areas is significant at the $95 \%$ confidence level based on a two-tailed Student's t-test

Correspondingly, in March, May, and November, there is also cooling in large areas of the mid-latitudes in the Pacific sector (i.e., east of the Eurasian continent). Similar to the Eurasian cooling situation, there are also anticyclonic circulation changes that correspond to mid-latitude cooling in the Pacific. Taken together, the mid-latitude cooling generally occurs in the region downstream (east) of the strongest Arctic warming; for example, Eurasian cooling occurs when the strongest Arctic warming is located farther west, as indicated in Fig. 2a.

As demonstrated in Sect. 5, the positive diabatic heating change in the Arctic sector is crucial in the Arctic and Eurasian connections. Hence, the seasonality in the regional averaged diabatic heating in the Arctic sector is further examined. As shown in Fig. 11, the positive diabatic heating (indicated by both $\dot{\theta}$ and $Q$ ) change in winter is much stronger than that in other seasons. The wintertime positive diabatic heating change generally decreases with height except for a turning in $\dot{\theta}$ roughly within the boundary layer (Fig. 11d, h). As a result, this vertical structure of diabatic heating generates negative potential vorticity according to potential vorticity dynamics (Hoskins et al. 1985). The negative potential vorticity further generates an 

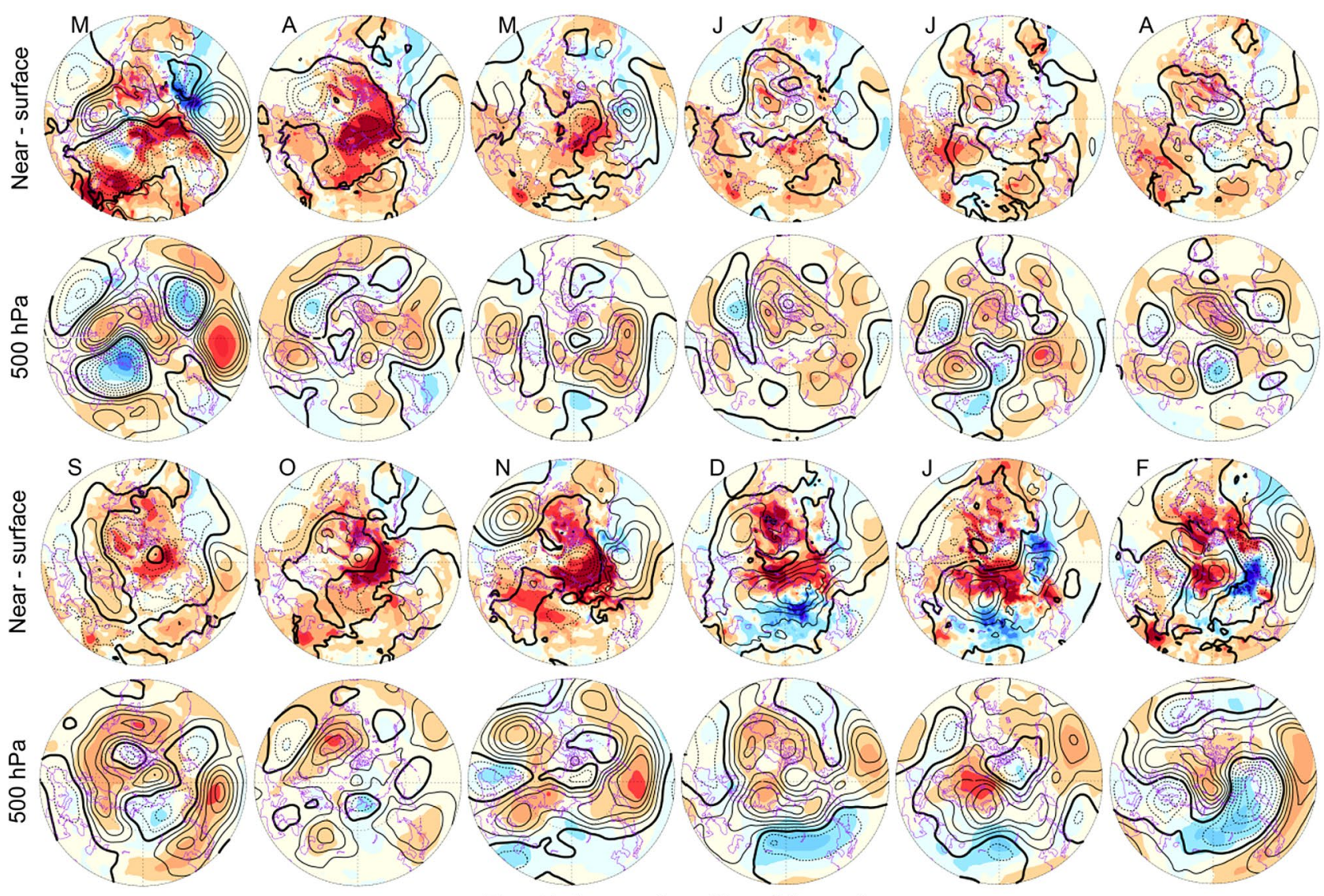

Trend in temperature ( $\mathrm{K}$ per 39 years)

$$
-6
$$

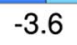

$-1.2$

1.2

3.6

6

Fig. 10 The first and third rows show the linear trend in the monthly mean temperature (filled) at the near-surface and sea level pressure (black contour, same intervals as Fig. 2a) from 1979 to 2017. The

anticyclonic circulation and expands its influence to midlatitudes through potential vorticity advection, as addressed in Xie et al. (2020). In contrast, the weaker diabatic heating changes in other seasons and the corresponding vertical structure generated different changes in the atmospheric circulation and temperature (Figs. 10, 11).

As already addressed in Sect. 3 (Fig. 2), Arctic warming and Eurasian cooling show baroclinic structures. From the view of potential vorticity dynamics, the importance of the baroclinicity lies in the potential vorticity gradients and corresponding potential vorticity advection in the mid-high latitudes (Luo et al. 2018; Xie et al. 2020). From a classic dynamic meteorology view, the baroclinicity is related to the horizontal temperature (or pressure and geopotential) gradients and corresponding temperature advection, e.g., the baroclinic wave. Figure 12a shows the vertical structure of the changes in temperature and geopotential height across the section of the warming and anticyclone centres (marked in Fig. 2a, c). As shown in Fig. 12a, throughout second and fourth rows show the linear trends in the monthly mean temperature (filled) and geopotential height (black contour, same intervals as Fig. 2c) at $500 \mathrm{hPa}$ from 1979 to 2017

the troposphere, the warming and anticyclone centres tilt westward with height, and the warming centre is located west of the anticyclone centre. Such a structure agrees well with the classic picture obtained from the two-layer model used to examine the baroclinic wave (e.g., addressed in Sect. 8.2 of Holton (2004)). The wind change at $500 \mathrm{hPa}$ can be reproduced by integrating the thermal wind relation (e.g., Eq. (3.30) in Holton (2004)) from the near-surface to $500 \mathrm{hPa}$. This result further confirms the key role of baroclinicity in the coupling of different vertical levels.

The baroclinic wave analogy indicates that the feedbacks among temperature advection and circulation are crucial in determining the temperature and circulation changes in the Arctic warming and Eurasian cooling sectors (Fig. 2a, c). Therefore, the simultaneous two-way interactions between the Arctic and mid-latitudes are crucial for wintertime circulation development in response to the enhanced sensible heat originating from summer over the eastern Arctic sector. Only when two-way interactions exist could dipoles in sensible 


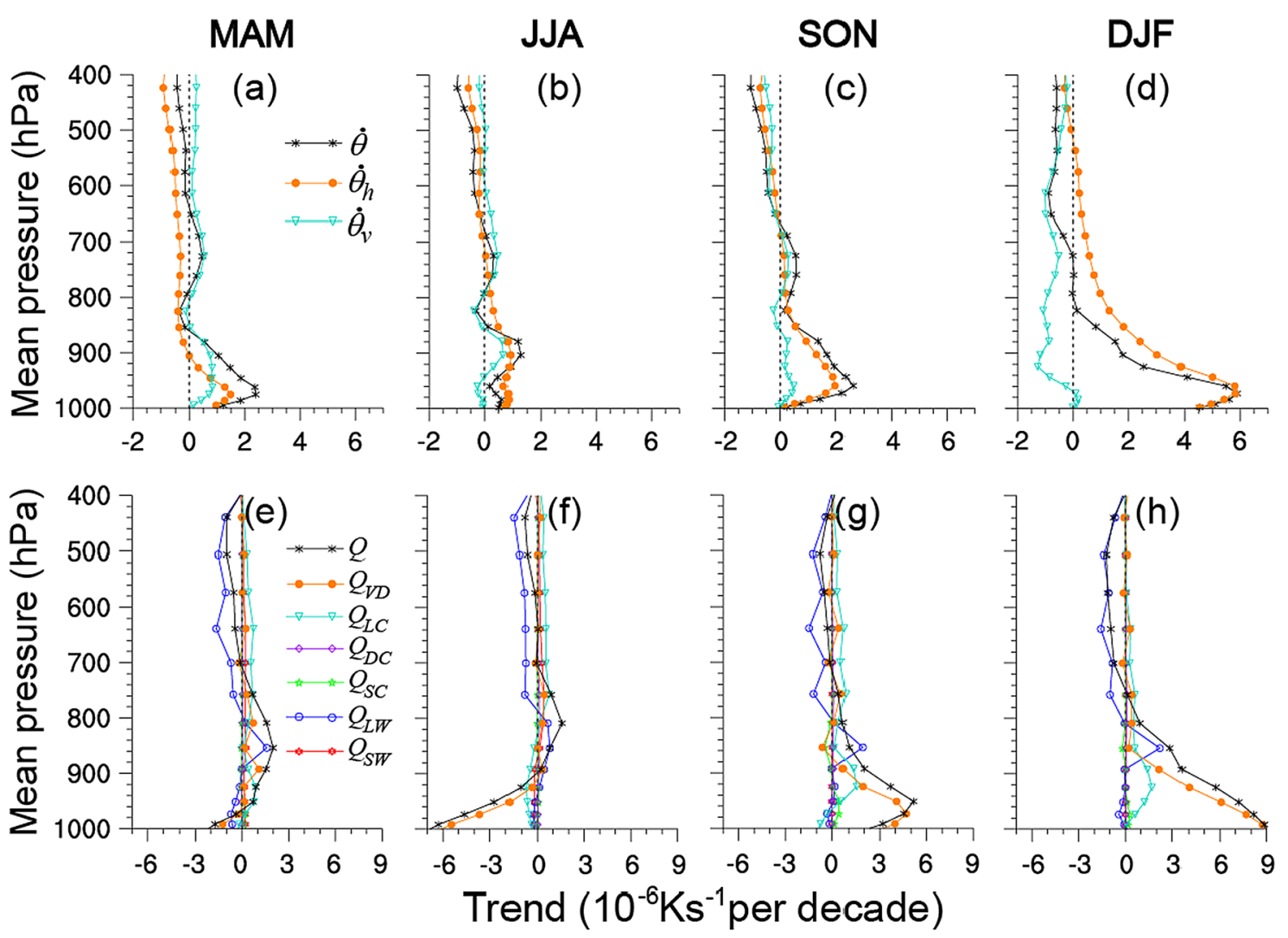

Fig. 11 a Vertical profile of the regional mean linear trends of $\dot{\theta}, \dot{\theta}_{h}$, and $\dot{\theta}_{v}$ from 1979 to 2017 during boreal spring averaged over [70
$\left.\mathrm{N}-90^{\circ} \mathrm{N}, 50^{\circ} \mathrm{E}-90^{\circ} \mathrm{E}\right]$. b-d Same as a but for the other three seasons. (Bottom) Same as (top) but for $Q$ (Eq. (4)) and its six components from NCEP-2 data
Fig. 12 a Vertical-latitudinal cross-section of the linear trend in temperature (filled) and geopotential height (blue contour) from 1979 to 2017 during boreal winter. The results are averaged over the region of $\left[75^{\circ}\right.$ $\left.\mathrm{N}-80^{\circ} \mathrm{N}\right]$ outlined by the green sector in Fig. 2a, c. b Linear trend in wind (blue vector) at $500 \mathrm{hPa}$ from 1979 to 2017 during boreal winter. The red vector indicates the result by integrating the thermal wind relation from the surface to $500 \mathrm{hPa}$ (a) Averaged over $\left[75^{\circ} \mathrm{N} \sim 80^{\circ} \mathrm{N}\right]$

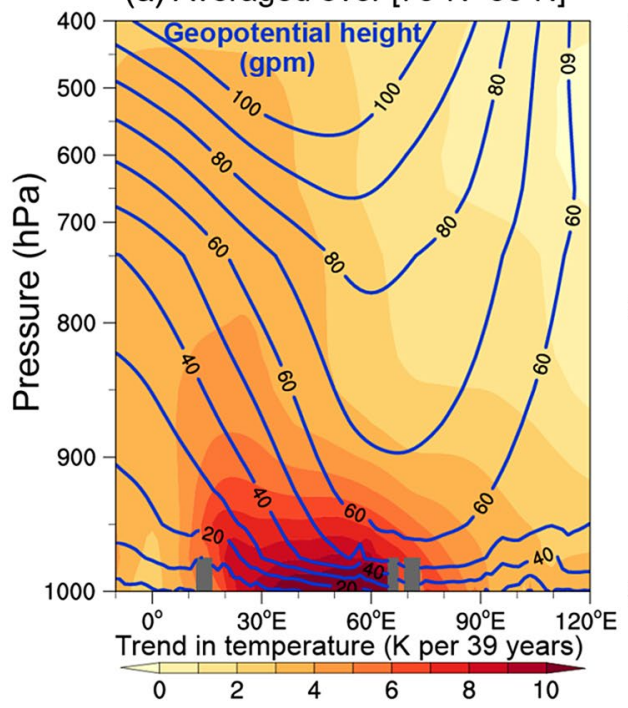

(b) Trend in wind at $500 \mathrm{hPa}$

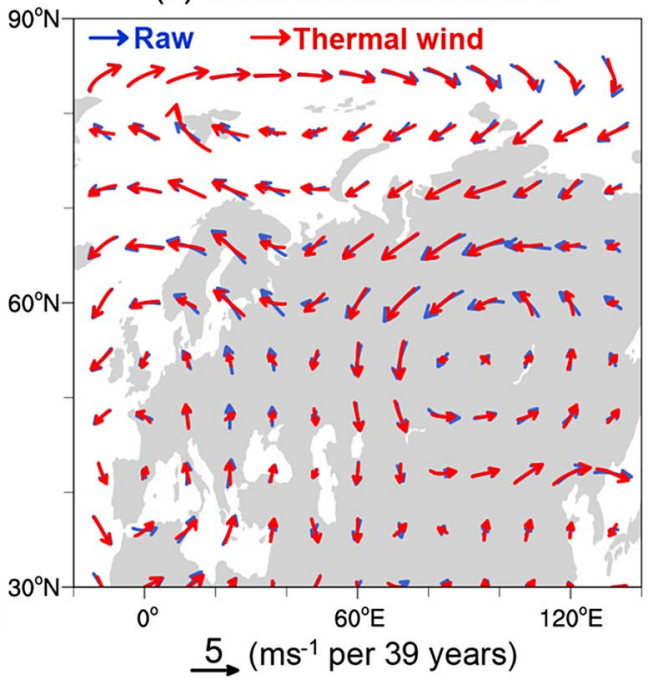

heat and diabatic heating, wide warming in the Arctic, and Eurasian cooling present. Namely, the strong intrinsic baroclinicity over the mid-high latitudes lays the background that local circulation change directly induced by the sensible heat change over the eastern Arctic sector can finally develop into a large-scale circulation anomaly and affect downstream Eurasia through the baroclinic wave or potential vorticity advection mechanisms. 
Regarding the dipole in sensible heat (Fig. 3e), the insignificant negative change in the western Arctic sector can be modulated by the eastern region through the development of baroclinic wave circulation. For example, the negative sensible heat change in the western sector corresponds to the reduced wind speed (figure not shown) and the anticyclonic circulation anomaly (Fig. 2a). Regarding the wide warming in the Arctic sector (Fig. 2a), the eastern sector is directly warmed by the vertical diffusion of enhanced sensible heat, while the western sector is warmed by horizontal advection so that the near-surface air temperature (Fig. 1a) warmed more than the surface skin temperature (Fig. 1b). This is clearly indicated by the decrease in the temperature difference between the surface skin and near-surface air over the western Arctic region (figure not shown). In addition, as discussed in Sect. 4, longwave radiation feedback is indispensable for the final wide warming. Eurasian cooling in winter is just a downstream development of the baroclinic wave circulation due to two-way interactions. Recent studies also suggest that the development of atmospheric circulation in winter is vital for Eurasian and Arctic connections in winter (e.g., Blackport et al. 2019; Blackport and Screen 2021; Zappa et al. 2021). Nonetheless, the summertime origin of the sensible heat change in winter suggests a driving role of the Arctic.

\section{The role of ocean heat transport and the complexity of interannual and decadal variability}

In the former sections, the situations concerning both the interior atmosphere and the Earth's surface have been examined. However, the situations beneath the Earth's surface have not yet been examined. In particular, the horizontal heat transport and local energy uptake by the subsurface ocean should be investigated further.

Figure 13 shows the change in the subsurface ocean potential temperature in the Arctic. The upper-level (0-20 m) ocean generally shows a warming trend; specifically, almost all the statistically significant changes are positive. Note that the depth of the mixed layer of the Arctic Ocean ranges from approximately $5 \mathrm{~m}$ to more than $100 \mathrm{~m}$ in varied seasons and locations (Peralta-Ferriz and Woodgate 2015). The overall magnitudes of the upper-level ocean warming in the Arctic Ocean (specifically, the Nordic seas) vary slightly in different seasons; specifically, they are slightly stronger in summer and autumn than in spring and winter (Fig. 13a-d). The seasonality in the subsurface ocean warming is very different from the warming in the atmosphere aloft (Figs. 10, 13). The most remarkable difference is the weakest warming in the atmosphere but the strongest warming in the subsurface ocean in summer relative to other seasons.
The warming in the deeper-level is generally identical to that in the upper-level (Fig. 13e-h). The warming in the Nordic seas (approximately $20^{\circ} \mathrm{W}-100^{\circ} \mathrm{E}$ ) is statistically significant (Fig. 13f) across all depths in summer when the strong energy uptake indicated by the energy budget at the Earth's surface occurs (Fig. 8). The warming in other seasons is less significant than that in summer. In winter, the most significant upper-level subsurface ocean warming occurs around the Barents-Kara seas (approximately $60^{\circ} \mathrm{E}$ ), which agrees with the warming in the atmosphere (Fig. 2a). The seasonality of warming in both the subsurface ocean and atmosphere (Figs. 10,13) further suggests that the ocean uptakes more energy in the summer (Figs. 8, 13) and then releases energy to the atmosphere through sensible heat in winter (Fig. 8) to favour the strongest atmospheric warming around the Barents-Kara seas (Fig. 2a).

Despite the trend, the aforementioned conclusions are further verified by examining the interannual and decadal variability. Figure 14 shows the time series of several important variables averaged over the regions $\left(70^{\circ} \mathrm{N}-90^{\circ} \mathrm{N}, 50^{\circ}\right.$ E-90 $90^{\circ}$ ) with positive sensible heat and diabatic heating changes in winter (Figs. 3e, 6a, b). The correlation among the original time series of the variables (the upper numbers in Fig. 14c) suggests that the storylines from the summertime sea ice to wintertime sensible heat, diabatic heating and temperature of the atmosphere, and sea ice still hold when the trend is not removed. The correlations among variables generally decreased after linear detrending (Fig. 14c). The correlations of the interannual variability are significant among the wintertime sensible heat, sea ice, and diabatic heating (Figs. 14, 15 bottom). The interannual variability in sea ice is also significantly correlated across seasons (between summer and winter). However, the persistent influence of summertime sea ice on the wintertime temperature and sensible heat is insignificant (Figs. 14c, 15h). Interestingly, relative to summertime sea ice, the summertime subsurface ocean heat anomaly is much better correlated with wintertime sensible heat (Fig. 15f, h). This indicates that the other factors despite sea ice have crucial impacts on subsurface ocean heat in summer on an interannual timescale. Therefore, the situation in interannual variability is more complex than the overall trend. The complexity mainly lies in the persistence of the influence of the summertime sea ice anomaly on winter (Fig. 17).

Regarding decadal variability, the whole period from 1979 to 2017 is separated by 1998 according to the different trends in temperature and sea ice (both summer and winter) during two periods (Fig. 14a). From 1979 to 1998, there was a slight cooling trend in the Arctic in winter and corresponded with the warming in east Eurasia (Fig. 15a). In contrast, the temperature change after 1998 is opposite to that before 1998 (Fig. 15a, b). The change during the whole period from 1979 to 2017 is dominated by the strong trend 

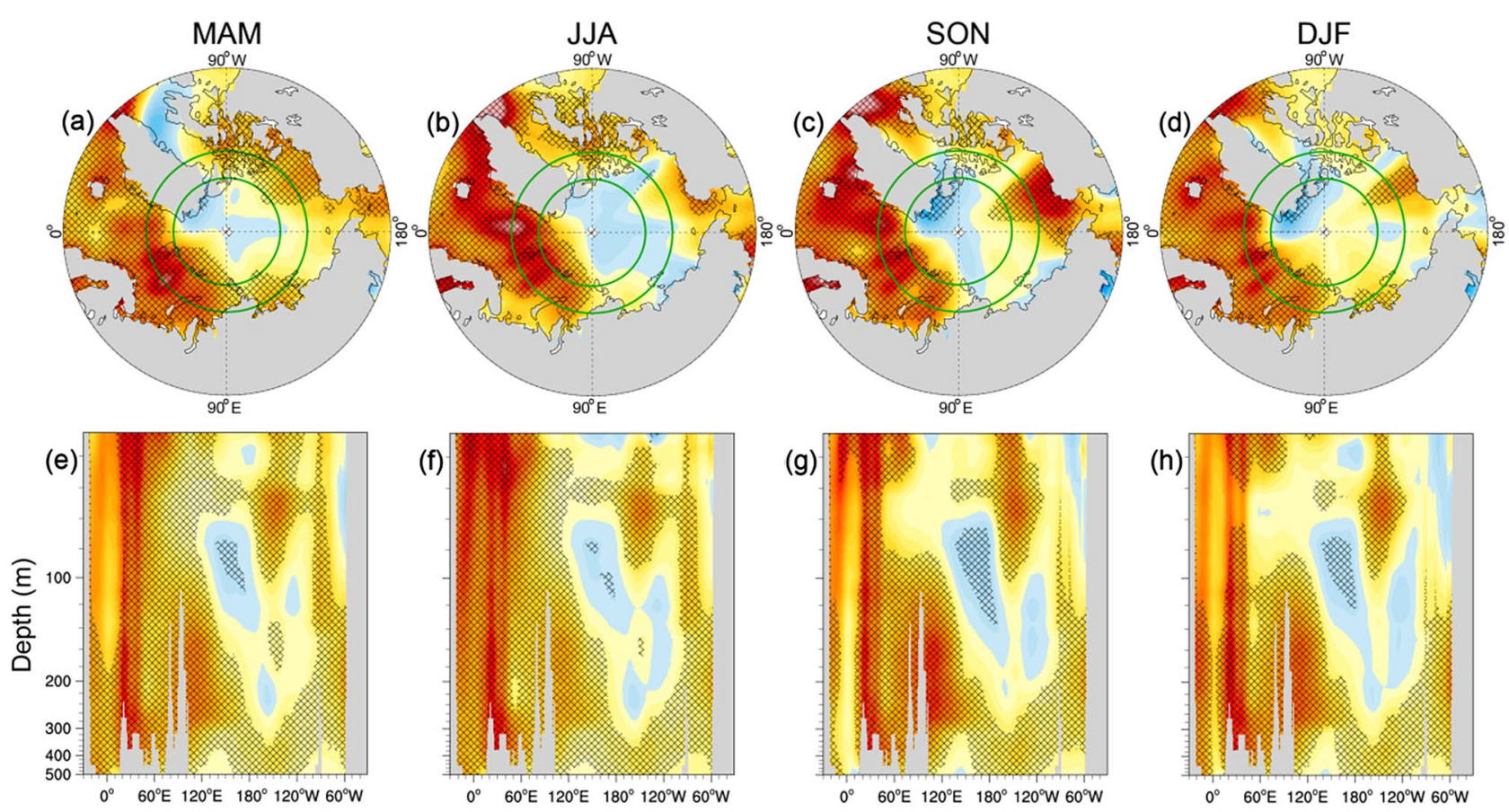

Trend in potential temperature ( $\mathrm{K}$ per 39 years)

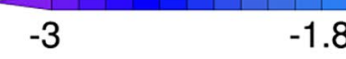

$-0.6$

0.6

1.8

3

Fig. 13 Linear trend in upper-level (averaged across approximately 0-20 m) subsurface ocean potential temperature from 1979 to 2017 during boreal spring (a), summer (b), autumn (c), and winter (d). (Bottom) The vertical-latitudinal cross-section corresponding to the

after 1998. The opposite changes before and after 1998 further confirm the wintertime Arctic and Eurasian dipole pattern revealed by the overall trend. Nonetheless, the sensible heat changes in the Arctic in winter before and after 1998 are not exactly opposite (Fig. 15c, d); namely, only the positive sensible heat change before 1998 in the western Arctic sector is opposite to the dipole sensible heat changes after 1998. On the one hand, this is probably because the magnitude of the sea ice change in summer before 1998 is not strong enough to induce persistent changes in energy processes from summer to winter. On the other hand, the importance of the two-way interactions (Sect. 6) in winter implies that the difference in the background (climatology) general circulation between the two periods could be another reason. Taken together, these investigations on decadal variability suggest that the magnitude of summertime sea ice change is crucial for a robust storyline from summertime sea ice to wintertime Eurasian cooling revealed by the results according to the overall trend (Fig. 17).

The role of horizontal subsurface ocean heat transport is also explored according to interannual variability. During the period with available horizontal subsurface ocean heat transport data (2004-2010, Sect. 2.4), 2005 and 2006 were chosen as anomalously warm (high in temperature, sensible top panel averaged over $\left[75^{\circ} \mathrm{N}-80^{\circ} \mathrm{N}\right.$ ] (marked by the green ring in a). The linear trend in the hatched areas is significant at the $95 \%$ confidence level based on a two-tailed Student's t-test

heat, and diabatic heating) and cold years in the Arctic in winter (Fig. 14b), respectively. As shown in Fig. S1, the interannual differences between the warm and cold years resemble the trend of several decades (Fig. 2a, c). Hence, the dynamic mechanism of the interior atmosphere is universal in terms of both the trend and interannual variability. However, the correspondence between the sea ice differences and other variables (Figs. 14b, 15h, S1) is much poorer than that of the trend (Figs. 3, 4, 5, 6, 7, 8, 9). Similar to the detrended correlation, the influence of sea ice is disturbed by other factors on the interannual timescale.

Regarding the horizontal subsurface ocean heat transport, the heat transport (entering the Arctic) across the Barents Sea opening (BSO) gateway in winter does not agree well with the temperature, sensible heat, and diabatic heating around the Barents-Kara seas (Figs. 14b, 16a). Nevertheless, the BSO heat transport is indeed larger in our chosen warm year (2005) than in the cold year (2006). For the interannual variability, the stronger horizontal oceanic heat transport across the BSO gateway favours a warmer southern Barents Sea from autumn to winter but not the whole Barents-Kara seas (Fig. 16c, d). Regarding the climatology, the horizontal oceanic heat transport across the BSO gateway seems to favour strong wintertime sensible heat and diabatic 


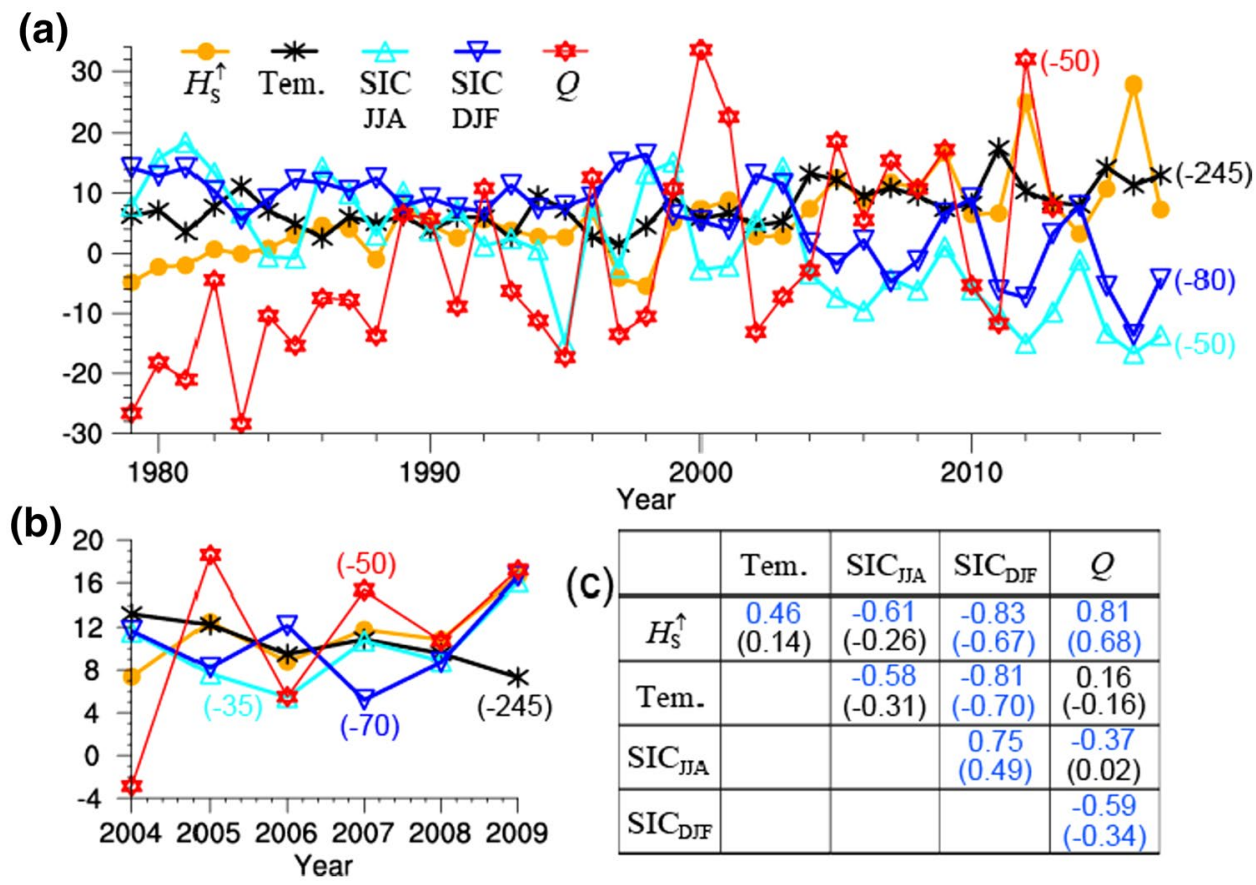

Fig. 14 a Time series of the regional mean (averaged over $\left[70^{\circ}\right.$ $\left.\mathrm{N}-90^{\circ} \mathrm{N}, 50^{\circ} \mathrm{E}-90^{\circ} \mathrm{E}\right]$ ) $H_{\mathrm{S}}^{\uparrow}$ (orange, $\mathrm{Wm}^{-2}$ ), near-surface air temperature (black, $\mathrm{K}$ ), sea ice concentration (SIC, blue, \%), and $Q$ (red, $10^{-6} \mathrm{Ks}^{-1}$ ) in boreal winter and SIC in boreal summer (cyan, \%) from 1979 to 2017 . For better illustration, some curves are vertically shifted by the magnitude marked by the number in the bracket. b Part

heating around the Barents-Kara seas (Fig. 16b). Regarding the overall trend, previous studies have suggested an increase in poleward BSO heat transport during the past several decades and the crucial contribution of BSO heat transport to sea ice decline in both the past and future (e.g., Arthun et al. 2012, 2019; Delworth et al. 2016; Tsubouchi et al. 2021). Therefore, the indirect effect of horizontal subsurface ocean heat transport on wintertime Eurasian cooling through its influence on sea ice needs to be further investigated.

\section{Concluding remarks}

From a general dynamic and thermodynamic coupling view, this paper investigated the linkages between Arctic warming and Eurasian cooling in winter since 1979. This study intends to build a comprehensive picture of the mechanisms concerning the key processes, including the featured wintertime atmospheric circulation patterns, wintertime energy budget at the Earth's surface and its summertime origins associated with the sea ice, the coupling between the energy budget at the Earth's surface and the diabatic heating of the atmosphere aloft in winter, the detailed seasonality in the circulation patterns and diabatic heating of the atmosphere, the crucial role of the baroclinicity, the situation concerning of a that truncated from 2004 to 2009. c The correlation coefficients among the variables shown in a. The upper numbers indicate the correlation coefficients of the original time series, while the bottom numbers in the bracket indicate the correlation coefficients after linear detrending. The correlation coefficient in blue is statistically significant at the $95 \%$ confidence level based on a two-tailed Pearson's r-test

the interannual and decadal variability, and the effect of the subsurface ocean heat transports. As summarized in Fig. 17, the storylines from summer to winter suggest a driving role of the Arctic in the wintertime Eurasian cooling. The major results and key points are summarized as follows:

1. The summertime origin of the positive sensible heat change in winter suggests a driving role of the Arctic. Although wintertime Eurasian cooling and Arctic warming are linked by a simultaneous prominent anticyclonic circulation change, this circulation change can be triggered by the enhanced sensible heat in the eastern Arctic sector, which originates from the summertime enhanced subsurface ocean heat uptake. Specifically, the changes in wintertime sensible heat and diabatic heating show a dipole pattern in the Arctic sector with negative and positive signs in the west and east, respectively, but the negative change is insignificant. Furthermore, the insignificant negative change in the western Arctic sector and the wide Arctic warming can be explained by the development of circulation triggered by the positive sensible heat in the east. The two-way interaction between the Arctic and mid-latitudes is crucial in circulation development in winter and is indispensable because the climatological background baroclinicity in 


\section{Linear trend}

(a) $1979-1998$

(b) 1998-2017

(c) $1979-1998$

(d) 1998-2017
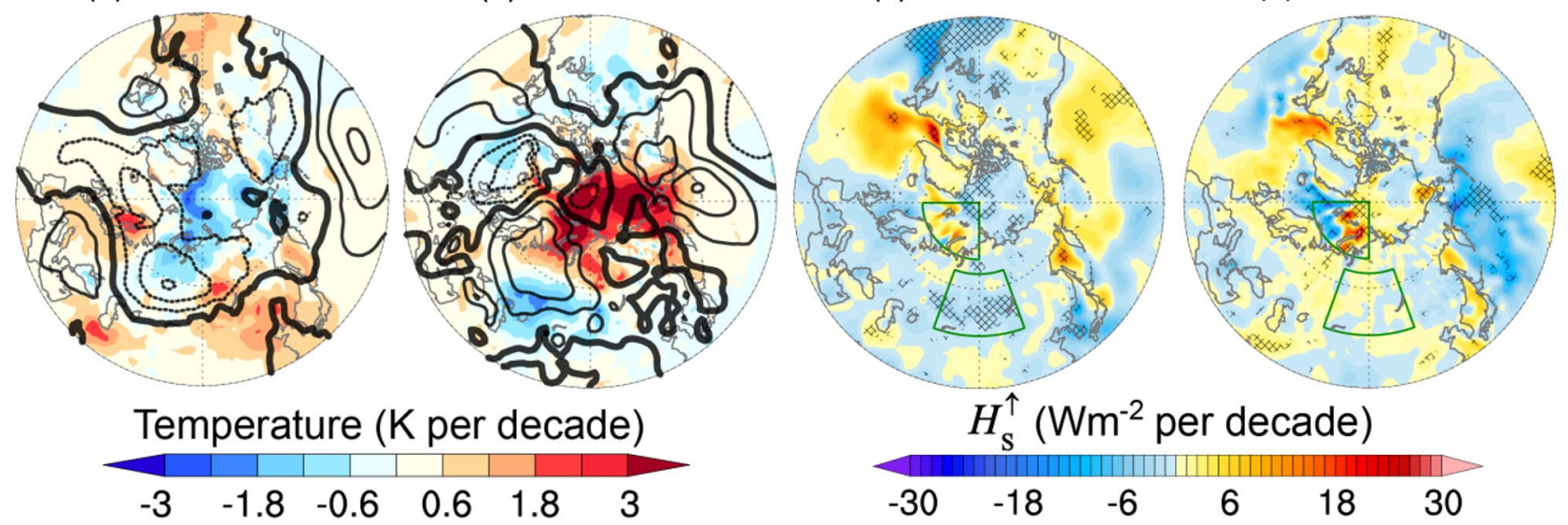

$\begin{array}{llllll}-30 & -18 & -6 & 6 & 18 & 30\end{array}$

\section{Detrended correlation coefficient with $H_{\mathrm{s}}^{\uparrow}$ in DJF}

(e) DJF Tem.

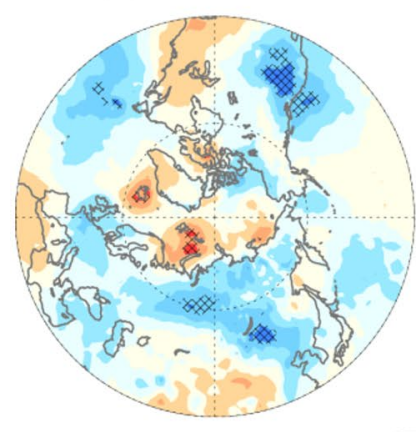

(f) JJA Ocn. Tem.

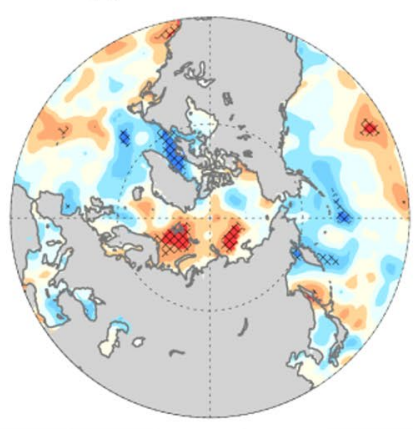

(g) DJF SIC

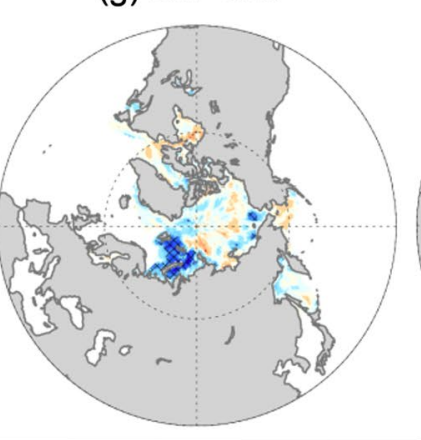

(h) JJA SIC

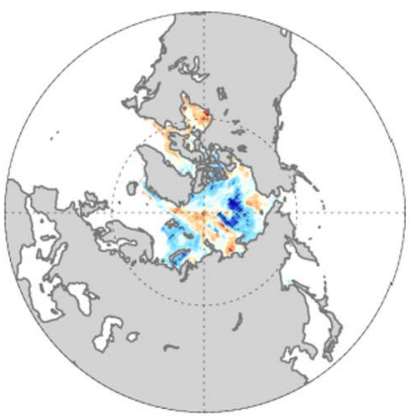

$-0.6 \quad-0.36 \quad-0.12$

Fig. 15 a Linear trend in temperature (filled) at the near-surface and sea level pressure (black contour) from 1979 to 1998 during boreal winter. The dashed and solid black lines represent negative and positive values, respectively; the interval is $1 \mathrm{hPa}$ and the thick line is zero. b Same as a but for trend from 1998 to 2017. c, d Same as a, b but for sensible heat $H_{\mathrm{S}}^{\uparrow}$. e The detrended correlation coefficient between near-surface air temperature and sensible heating in win- ter. $\mathbf{f}-\mathbf{h}$ Same as a but for correlation of JJA mean subsurface ocean temperature (f), sea ice concentration in DJF (g) and JJA (h) with sensible heating in winter. The hatched areas indicate that the linear trend and correlation coefficient are statistically significant at the 95\% confidence level based on the two-tailed Student's t-test and Pearson's r-test, respectively mid-high latitudes is strong. Consequently, the feedback between temperature advection and circulation development resembling the baroclinic wave mechanism favours both Arctic warming and downstream Eurasian cooling. The seasonality of the change demonstrates that the Arctic and mid-latitude connections resembling the wintertime situation can also occur in other months. Mid-latitude cooling generally occurs in the downstream region of the strongest Arctic warming. Hence, Eurasian cooling occurs when the strongest Arctic warming is located over the western or middle flank to the north of the Eurasian continent. Since the diabatic heating around the Barents-Kara seas is strongest in winter, Eurasian cooling only occurs in winter.

2. Summertime enhanced oceanic heat uptake in the eastern Arctic sector is regulated by the strong sea ice decline and corresponding sea ice-albedo feedback. Sea ice is crucial in the energy cycle across seasons although longwave radiation feedback can amplify the magnitude of change and is indispensable in forming energy budget equilibrium (Dai et al. 2019). Summertime sea ice loss favours energy uptake, while wintertime sea ice loss favours energy release. Upper-level subsurface ocean warming is also enhanced around the Barents-Kara seas. 
(a)
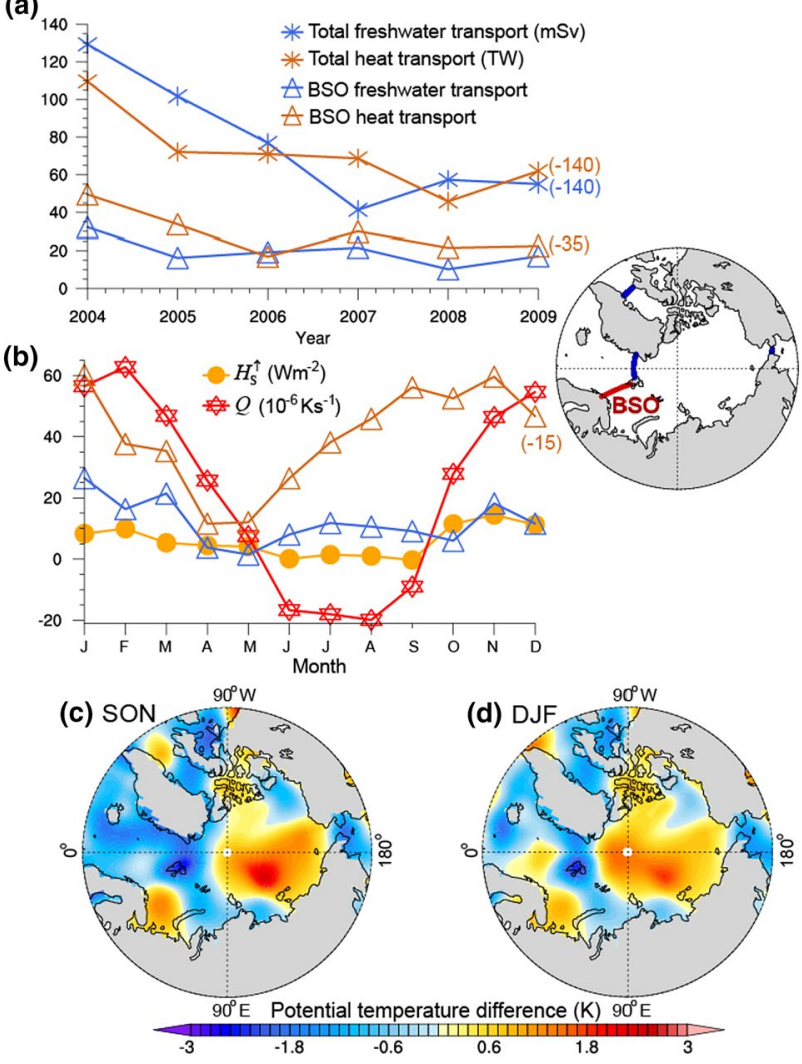

Fig. 16 a Time series of freshwater (blue, $\mathrm{mSv}=10^{3} \mathrm{~m}^{3} \mathrm{~s}^{-1}$ ) and heat (brown, $\mathrm{TW}=10^{12} \mathrm{~W}$ ) transports through the Arctic gateways from 2004 to 2009. The data are introduced in Sect. 2.4. The asteriskmarked curves indicate the total transport through all the Arctic gateways (marked by the thick blue and red lines in the right attached figure). The triangle-marked curves indicate the transports through the Barents Sea opening (BSO) gateways. b Climatology (2004-2009) of the monthly mean freshwater (blue) and heat (brown) transport through the BSO gateway, and regional mean (averaged over $\left[70^{\circ}\right.$ $\left.\left.\mathrm{N}-90^{\circ} \mathrm{N}, 50^{\circ} \mathrm{E}-90^{\circ} \mathrm{E}\right]\right) H_{\mathrm{S}}^{\uparrow}$ (orange, $\mathrm{Wm}^{-2}$ ) and $Q\left(\right.$ red, $10^{-6} \mathrm{Ks}^{-1}$ ). For better illustration, some curves are vertically shifted by the magnitude marked by the number in the bracket. c, d Same as Fig. 13c, d but for the differences (2005 minus 2006)

The seasonality of subsurface ocean warming further suggests that the subsurface ocean uptakes more energy in summer and then releases energy to the atmosphere in winter to favour the strongest atmospheric warming around the Barents-Kara seas in observations. Model simulations by Lainé et al. (2016) and Yoshimori et al. (2017) also support this conclusion. Additionally, the analysis of the interannual variability suggests that horizontal subsurface ocean heat transport can warm the southern Barents-Kara seas. Regarding the overall trend, previous studies have suggested an increase in poleward heat transport during the past several decades and argued for its crucial contribution to Arctic sea ice loss and warming (e.g., Årthun et al. 2012, 2019; Delworth et al. 2016; Tsubouchi et al. 2021).
Some discussions are addressed here. First, regarding Arctic warming, this study examines the enhanced warming around the Barents-Kara seas rather than the overall Arctic warming (Fig. 17). Therefore, the insignificant influences of overall Arctic warming on the mid-latitude climate, such as those suggested in Dai and Song (2020) and Blackport and Screen (2020a), do not contradict our findings. Additionally, the proposed causes of the overall Arctic warming, such as the effect of the moist processes addressed in $\mathrm{Lu}$ and Cai (2009) and Graversena and Burtu (2016), cannot be imposed on the regional enhanced warming around the Barents-Kara seas.

Second, it must be noted that the variability or changes in sea ice and temperature in the Arctic are not necessarily synced. One reason is that sea ice is directly linked to the energy budget at the Earth's surface and diabatic heating of the atmosphere (as addressed in Sects. 4 and 5) rather than temperature. The diabatic heating of the atmosphere is determined by dynamic (e.g., circulation) and thermodynamic (e.g., temperature) coupling. Hence, the effect of sea ice cannot be solely evaluated by its relation with temperature. Additionally, this study suggests that diabatic heating of the atmosphere should be emphasized when evaluating the dynamic connections between the Arctic and the midlatitudes. Previous studies further propose that the vertical structure of warming and diabatic heating in the Arctic is important. For example, model simulations suggest that diabatic heating further from the surface and corresponding deep warming in the Arctic are more effective at perturbing the mid-latitude climate (He et al. 2020; Kim et al. 2021). Ultimately, the robustness of the remote influence of Arctic warming is determined by whether diabatic heating can significantly provoke large-scale circulation anomalies (He et al. 2020; Labe et al. 2020; Xie et al. 2020; Kim et al. 2021). Especially in a much warmer and moister future climate, the latent heat of condensation may increase due to higher environmental moisture. The vertical structure of diabatic heating change in the Arctic could also be different from that during the past decades (e.g., Kim et al. 2021). Hence, the effect of total turbulent heat flux (i.e., sensible and latent heat flux) should be considered rather than only sensible heat in this study.

Third, the situation in the interannual variability is more complex than the overall trend (Fig. 17). Since the Arctic is characterized by the trend, the trend and its influence are the major concerns. The multilink mechanisms suggested by the analysis of the trend are only partly confirmed by the analysis of the interannual variability. In particular, the persistence of the influence of summertime sea ice is not significantly established in terms of interannual variability. A key reason for the complexity in interannual variability may lie in the influences of internal chaotic atmospheric variability and internal climate variability on the Arctic. 
Fig. 17 A schematic view of the scope and key points of this study. The scope of this paper is, (1) the regional enhanced warming in Barents-Kara seas rather than warming in the whole Arctic (top); (2) storylines from summer to winter (gradient colored arrow on left); (3) focus on the overall trend and with comparisons to decadal and interannual variability (the right part). The key processes concerning the mechanisms are listed on the left part

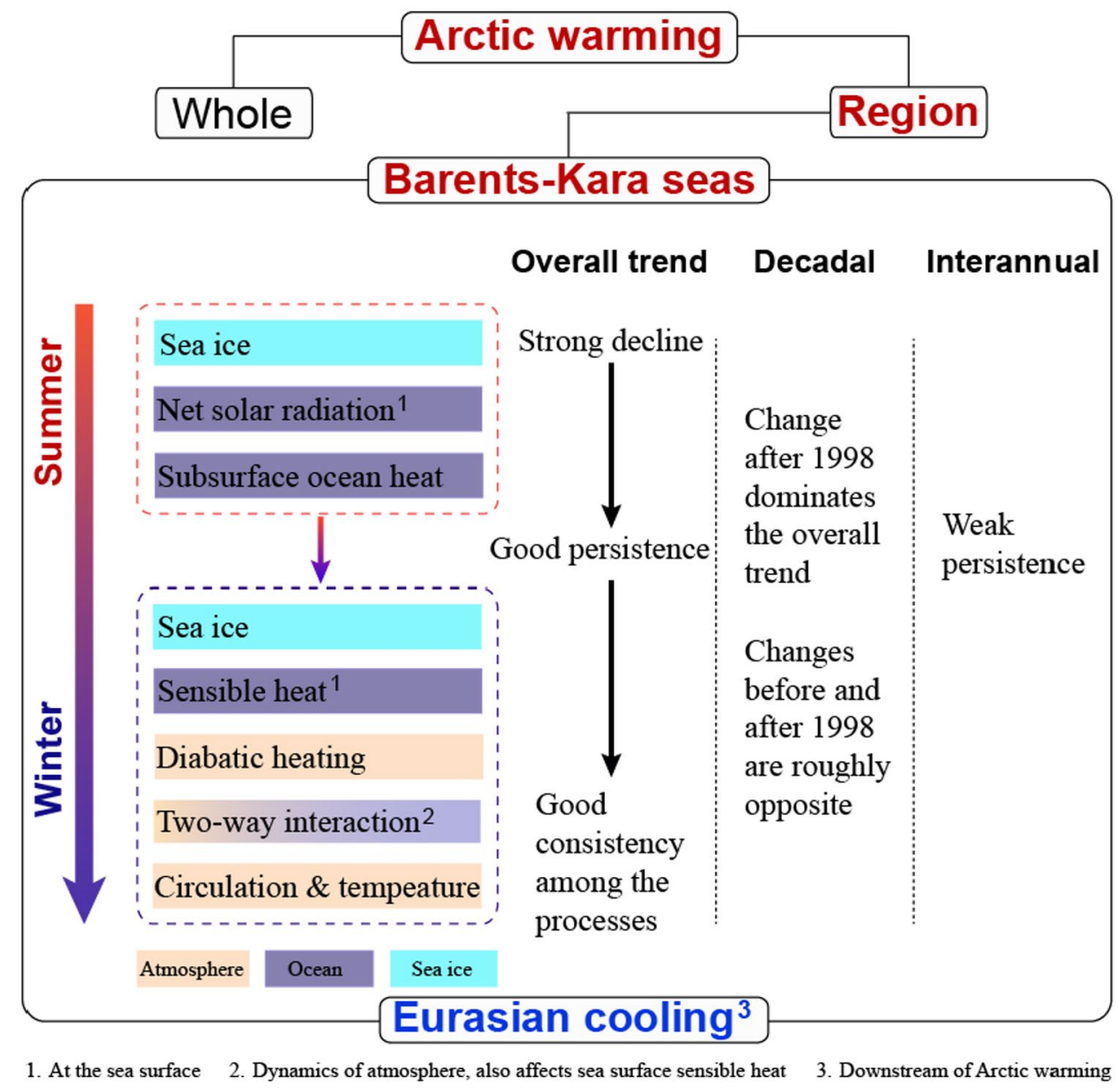

For example, Sorokina et al. (2016) and Blackport and Screen (2021) suggest that atmospheric variability is crucial in determining the observed variability in wintertime sea ice, corresponding turbulent heat flux, and Eurasian temperature. As addressed in Sect. 6, their results are reasonable because the importance of background baroclinicity indicates the importance of atmospheric variability and the two-way interactions between the Arctic and the mid-latitudes. The small influence of wintertime sea ice loss on Eurasian cooling suggested by model simulations, such as Blackport et al. (2019), may also be because the sea ice change in the model cannot well reproduce the observed atmospheric variability, the two-way interactions, the corresponding energy budget at the Earth's surface and the diabatic heating of the atmosphere. The influence of internal climate variability (e.g., El Niño) on the Arctic and Eurasia also complicates the issue of interannual or decadal variability (e.g., Guan et al. 2015; Ding et al. 2018; Matsumura and Kosaka 2019; Mori et al. 2019). Nonetheless, the driving role of the Arctic is suggested because the summertime origin of the wintertime changes in multiple variables in the eastern Arctic sector and the wintertime changes (negative sensible heat and wide warming in the Arctic) in the western Arctic sector can be explained by the circulation development triggered by the eastern Arctic.

The final remarks are about the role of horizontal subsurface ocean heat transport and the model divergence. Section 7 partly shows the role of horizontal oceanic heat transport according to the results in interannual variability. Other aspects, such as the indirect effect of horizontal subsurface ocean heat transport on wintertime Eurasian cooling through its influence on sea ice, need to be further investigated. Future expected studies should combine multisource observations with model simulations, such as a combination of Laîné et al. (2016) and Barton (2019). Our findings are helpful in understanding the divergent interpretations of the observed or simulated results (e.g., Smith et al. 2019; Cohen et al. 2020). Specifically, the differences in all the processes proposed in this study among different models should be investigated. The key factors include the energy budget at the Earth's surface, diabatic heating and baroclinicity of the atmosphere, and the subsurface ocean heat states. In short, the dynamics revealed in this study help to interpret and evaluate the model simulations in further research. 
Supplementary Information The online version contains supplementary material available at https://doi.org/10.1007/s00382-021-06029-8.

Acknowledgements We thank four anonymous reviewers for constructive and helpful comments, which were very helpful in improving our paper. We thank the ECMWF, NCEP-DOE, Met Office Hadley Centre, Tsubouchi Takamasa and his coworkers for making their data available. This work is supported by the National Natural Science Foundation of China (41730963, 91937302 and 42030602), the Fundamental Research Funds for the Central Universities (lzujbky-2021-kb12, lzujbky-2021-sp07), and the Gansu Provincial Special Fund Project for Guiding Scientific and Technological Innovation and Development (2019ZX-06).

Open Access This article is licensed under a Creative Commons Attribution 4.0 International License, which permits use, sharing, adaptation, distribution and reproduction in any medium or format, as long as you give appropriate credit to the original author(s) and the source, provide a link to the Creative Commons licence, and indicate if changes were made. The images or other third party material in this article are included in the article's Creative Commons licence, unless indicated otherwise in a credit line to the material. If material is not included in the article's Creative Commons licence and your intended use is not permitted by statutory regulation or exceeds the permitted use, you will need to obtain permission directly from the copyright holder. To view a copy of this licence, visit http://creativecommons.org/licenses/by/4.0/.

\section{References}

Alexander MA, Bhatt US, Walsh JE, Timlin MS, Miller JS, Scott JD (2004) The atmospheric response to realistic Arctic Sea Ice anomalies in an AGCM during Winter. J Clim 17:890-905

Årthun M, Eldevik T, Smedsrud LH, Skagseth $\varnothing$, Ingvaldsen RB (2012) Quantifying the influence of Atlantic heat on Barents sea ice variability and retreat. J Clim 25(13):4736-4743

Årthun M, Eldevik T, Smedsrud LH (2019) The role of Atlantic heat transport in future Arctic Winter Sea Ice Loss. J Clim 32:3327-3341

Barton BI (2019) Climate change in the Barents Sea: ice-ocean interactions, water mass formation and variability. Oceanography. Université de Bretagne occidentale, Brest, English (NNT:2019BRES0053)

Berrisford P, Kållberg P, Kobayashi S et al (2011b) Atmospheric conservation properties in ERA-Interim. Q J R Meteorol Soc 137:1381-1399

Berrisford $\mathrm{P}$ et al (2011a) The ERA-Interim archive, version 2.0. ERA Report Series No. 1. https://www.ecmwf.int/en/elibrary/8174-erainterim-archive-version-20

Blackport R, Screen J (2020a) Insignificant effect of Arctic amplification on the amplitude of midlatitude atmospheric waves. Sci Adv 6:eaay 2880

Blackport R, Screen J (2020b) Weakened evidence for mid-latitude impacts of Arctic warming. Nat Clim Chang 10:1065-1066

Blackport R, Screen J (2021) Observed statistical connections overestimate the causal effects of Arctic Sea Ice Changes on Midlatitude Winter Climate. J Clim 34(8):3021-3038

Blackport R, Screen JA, van der Wiel K, Bintanja R (2019) Minimal influence of reduced Arctic sea ice on coincident cold winters in mid-latitudes. Nat Clim Change 9:697-704

Cai M (2005) Dynamical amplification of polar warming. Geophys Res Lett 32:L22710
Chiodo G, Haimberger L (2010) Interannual changes in mass consistent energy budgets from ERA-Interim and satellite data. J Geophys Res 115:D02112

Cohen J et al (2014) Recent Arctic amplification and extreme midlatitude weather. Nat Geosci 7:627-637

Cohen J, Zhang X, Francis J et al (2020) Divergent consensuses on Arctic amplification influence on midlatitude severe winter weather. Nat Clim Chang 10:20-29

Dai A, Song M (2020) Little influence of Arctic amplification on midlatitude climate. Nat Clim Change 10:231-237

Dai A, Luo D, Song M, Liu J (2019) Arctic amplification is caused by sea-ice loss under increasing CO2. Nat Commun 10:121

Dee DP et al (2011) The ERA-Interim reanalysis: configuration and performance of the data assimilation system. Q J R Meteor Soc 137:553-597

Delworth T, Zeng F, Vecchi G, Yang X, Zhang L, Zhang RH (2016) The North Atlantic Oscillation as a driver of rapid climate change in the Northern Hemisphere. Nat Geosci 9:509-512

Ding Q, Schweiger A, Heureux LM et al (2018) Fingerprints of internal drivers of Arctic sea ice loss in observations and model simulations. Nat Geosci 12:28-33

Francis JA, Vavrus SJ (2015) Evidence for a wavier jet stream in response to rapid Arctic warming. Environ Res Lett 10:014005

Good S, Martin M, Rayner N (2013) EN4: Quality controlled ocean temperature and salinity profiles and monthly objective analyses with uncertainty estimates. J Geophys Res 118:6704-6716

Gouretski V, Reseghetti F (2010) On depth and temperature biases in bathythermograph data: development of a new correction scheme based on analysis of a global ocean database. Deep Sea Res I 57:812-833

Graversen R, Burtu M (2016) Arctic amplification enhanced by latent energy transport of atmospheric planetary waves. Q J R Meteorol Soc 142:2046-2054

Guan X, Huang J, Guo R et al (2015) The role of dynamically induced variability in the recent warming trend slowdown over the Northern Hemisphere. Sci Rep 5:12669

He M, Hu Y, Chen N et al (2019) High cloud coverage over melted areas dominates the impact of clouds on the albedo feedback in the Arctic. Sci Rep 9:9529

He S, Xu X, Furevik T et al (2020) Eurasian cooling linked to the vertical distribution of Arctic Warming. Geophys Res Lett 47:e2020GL087212

Hill S, Ming Y, Held I et al (2017) A moist static energy budge-based analysis of the Sahel rainfall response to uniform oceanic warming. J Clim 30:5637-5660

Holland MM, Bitz CM (2003) Polar amplification of climate change in coupled models. Clim Dyn 21:221-232

Holopainen E, Fortelius C (1986) Accuracy of estimates of atmospheric large-scale energy Flux divergence. Mon Weather Rev 114:1910-1921

Holton JR (2004) An introduction to dynamic meteorology. Academic Press, Cambridge

Honda M, Inoue J, Yamane S (2009) Influence of low Arctic sea-ice minima on anomalously cold Eurasian winters. Geophys Res Lett 36:L08707

Hoskins BJ, Mcintyre ME, Robertson AW (1985) On the use and significance of isentropic potential vorticity maps. Q J R Meteorol Soc 111:877-946

Huang J, Xie Y, Guan X, Li D, Ji F (2017) The dynamics of the warming hiatus over the Northern Hemisphere. Clim Dyn 48:429-446

Iwasaki T, Shoji T, Kanno Y et al (2014) Isentropic analysis of polar cold airmass streams in the Northern Hemispheric Winter. J Atmos Sci 71:2230-2243

Kanamitsu M, Ebisuzaki W, Woollen J et al (2002) NCEP-DOE AMIPII Reanalysis (R-2). Bull Am Meteor Soc 83:1631-1643 
Kapsch M, Graversen R, Tjernström M (2013) Springtime atmospheric energy transport and the control of Arctic summer sea-ice extent. Nat Clim Chang 3:744-748

Kim D, Kang SM, Merlis TM et al (2021) Atmospheric circulation sensitivity to changes in the vertical structure of polar warming. Geophys Res Lett 48:e2021GL094726

Labe Z, Peings Y, Magnusdottir G (2020) Warm Arctic, Cold Siberia pattern: role of full Arctic amplification versus sea ice loss alone. Geophys Res Lett 47:e2020GL088583

Laîné A, Yoshimori M, Abe-Ouchi A (2016) Surface Arctic amplification factors in CMIP5 models: land and oceanic surfaces and seasonality. J Clim 29:3297-3316

Li X, Wu Z, Li Y (2019) A link of China warming hiatus with the winter sea ice loss in Barents-Kara Seas. Clim Dyn 53:2625-2642

Lindsay R, Wensnahan M, Schweiger A et al (2014) Evaluation of seven different atmospheric reanalysis products in the Arctic. $\mathrm{J}$ Clim 27:2588-2606

Liu Y, Key J (2016) Assessment of Arctic cloud cover anomalies in atmospheric reanalysis products using satellite data. J Clim 29:6065-6083

Lu J, Cai M (2009) Seasonality of polar surface warming amplification in climate simulations. Geophys Res Lett 36:L16704

Luo D, Xiao Y, Diao Y, Dai A, Franzke CL, Simmonds I (2016) Impact of Ural blocking on winter warm Arctic-cold Eurasian anomalies. Part II: The link to the North Atlantic Oscillation. J Climate 29:3949-3971

Luo D, Chen X, Dai A, Simmonds I (2018) Changes in atmospheric blocking circulations linked with winter Arctic Warming: a new perspective. J Clim 31:7661-7678

Matsumura S, Kosaka Y (2019) Arctic-Eurasian climate linkage induced by tropical ocean variability. Nat Commun 10:3441

Mori M, Kosaka Y, Watanabe M, Nakamura H, Kimoto M (2019) A reconciled estimate of the influence of Arctic sea-ice loss on recent Eurasian cooling. Nat Clim Change 9:123-129

Mori M, Kosaka Y, Watanabe M, Nakamura H, Kimoto M (2021) Reply to: Eurasian cooling in response to Arctic sea-ice loss is not proved by maximum covariance analysis. Nat Clim Change 11:109-111

Nakamura T, Yamazaki K, Iwamoto K, Honda M, Miyoshi Y, Ogawa Y, Ukita J (2015) A negative phase shift of the winter AO/NAO due to the recent Arctic sea-ice reduction in late autumn. J Geophys Res 120:3209-3227

Nigam S (1994) On the dynamical basis for the Asian summer monsoon rainfall-El Niño relationship. J Clim 7:1750-1771

Papritz L, Spengler T (2015) Analysis of the slope of isentropic surfaces and its tendencies over the North Atlantic. Q J R Meteorol Soc 141:3226-3238

Peralta-Ferriz C, Woodgate R (2015) Seasonal and interannual variability of pan-Arctic surface mixed layer properties from 1979 to 2012 from hydrographic data, and the dominance of stratification for multiyear mixed layer depth shoaling. Prog Oceanogr 134:19-53

Rayner NA et al (2003) Global analyses of sea surface temperature, sea ice, and night marine air temperature since the late nineteenth century. J Geophys Res Atmos 108:4407

Schneider T, Bischoff T, Płotka H (2015) Physics of changes in synoptic midlatitude temperature variability. J Clim 28:2312-2331

Screen JA, Simmonds I (2013) Exploring links between Arctic amplification and mid-latitude weather. Geophys Res Lett 40:959-964
Sheng C, Wu G, Tang Y et al (2021) Characteristics of the potential vorticity and its budget in the surface layer over the Tibetan plateau. Int J Climatol 41:439-455

Shepherd TG (2016) Effects of a warming Arctic. Science 353:989-990

Smith DM et al (2019) The Polar Amplification Model Intercomparison Project (PAMIP) contribution to CMIP6: investigating the causes and consequences of polar amplification. Geosci Model Dev 12:1139-1164

Sorokina S, Li C, Wettstein J et al (2016) Observed atmospheric coupling between Barents sea ice and the Warm-Arctic Cold-Siberian anomaly pattern. J Clim 29:495-511

Stouffer RJ, Manabe S (2017) Assessing temperature pattern projections made in 1989. Nat Clim Change 7:163-165

Taylor KE (2001) Summarizing multiple aspects of model performance in a single diagram. J Geophys Res Atmos 106:7183-7192

Trenberth K (1991) Climate diagnostics from global analyses: conservation of mass in ECMWF analyses. J Clim 4:707-722

Tsubouchi T, von Appen W-J, Schauer U, Kanzow T, Lee C, Curry B, de Steur L, Ingvaldsen R, Woodgate R (2019) The Arctic Ocean volume, heat and fresh water transports time series from October 2004 to May 2010. PANGAEA. https://doi.org/10.1594/PANGA EA.909966

Tsubouchi T, Våge K, Hansen B et al (2021) Increased ocean heat transport into the Nordic Seas and Arctic Ocean over the period 1993-2016. Nat Clim Change 11:21-26

Winton M (2006) Amplified Arctic climate change: what does surface albedo feedback have to do with it? Geophys Res Lett 33:L03701

Xie Y, Huang J, Ming Y (2019) Robust regional warming amplifications directly following the anthropogenic emission. Earth's Future 7:363-369

Xie Y, Wu G, Liu Y, Huang J (2020) Eurasian cooling linked with arctic warming: insights from PV dynamics. J Clim 33:2627-2644

Yanai M, Esbensen S, Chu J-H (1973) Determination of bulk properties of tropical cloud clusters from large-scale heat and moisture budgets. J Atmos Sci 30:611-627

Yang X-Y, Yuan X, Ting M (2016) Dynamical link between the Barents-Kara Sea Ice and the Arctic Oscillation. J Clim 29:5103-5122

Yeh T-C, Chu P-C (1958) Some fundamental problems of the general circulation of the atmosphere (in Chinese). Science Press, Beijing

Yoshimori M, Abe-Ouchi A, Laîné A (2017) The role of atmospheric heat transport and regional feedbacks in the Arctic warming at equilibrium. Clim Dyn 49:3457-3472

Zappa G, Ceppi P, Shepherd TG (2021) Eurasian cooling in response to Arctic sea-ice loss is not proved by maximum covariance analysis. Nat Clim Change 11:106-108

Zhang P, Wu Y, Simpson IR, Smith KL, Zhang X, De B, Callaghan P (2018) A stratospheric pathway linking a colder Siberia to Barents-Kara Sea sea ice loss. Sci Adv 4:eaat6025

Zhang P, Wu Z, Li J et al (2020) Seasonal prediction of the northern and southern temperature modes of the East Asian winter monsoon: the importance of the Arctic sea ice. Clim Dyn $54: 3583-3597$

Publisher's Note Springer Nature remains neutral with regard to jurisdictional claims in published maps and institutional affiliations. 